\title{
Seismic Response of Base-lsolated Buildings With High Damping Rubber Bearings Having Different Design Characteristics
}

\author{
Ahmet Hilmi DERINGÖL ( $\sim$ aderingol@gmail.com ) \\ Gaziantep Universitesi https://orcid.org/0000-0002-2665-8674

\section{Esra Mete Güneyisi} \\ Gaziantep Universitesi
}

\section{Original Article}

Keywords: Base isolation, Bearing property, High damping rubber bearing, Isolation parameter, Nonlinear response, Steel frame

Posted Date: February 2nd, 2021

DOl: https://doi.org/10.21203/rs.3.rs-161883/v1

License: (c) (i) This work is licensed under a Creative Commons Attribution 4.0 International License.

Read Full License 


\title{
Seismic response of base-isolated buildings with high damping rubber bearings having different design characteristics
}

\author{
Ahmet Hilmi Deringöl ${ }^{\mathrm{a}, *}$ and Esra Mete Güneyisi ${ }^{\mathrm{a}}$ \\ ${ }^{a}$ Department of Civil Engineering, Gaziantep University, 27310, Gaziantep, Turkey \\ ${ }^{*}$ Corresponding author: Tel: +90-342-3172400, Fax: +90-342-3601107, E-mail: ad20401@ mail2.gantep.edu.tr
}

\begin{abstract}
In this study, the use of high damping rubber bearing (HDRB) with various design properties in mitigating the seismic effects for steel buildings was investigated. For this, a generalized demand on the analytical model of HDRB was introduced and eighteen different models of HDRB were examined comparatively. These models were created by considering three significant isolation parameters of $\operatorname{HDRB}$ such as isolation period $\mathrm{T}(2,2.5$, and $3 \mathrm{~s}$ ), effective damping ratio $\beta_{\text {eff }}(0.05,0.10,0.15)$, and post-yield stiffness ratio $\lambda$ ( 3 and 6$)$. The benchmark low (3-storey), mid (6-storey), and high-rise (9-storey) steel buildings were equipped with different isolation systems of HDRB and then subjected to a set of earthquake ground motions through nonlinear time history analyses in order to evaluate the actual nonlinear behaviour of the bearings in the base-isolated steel buildings in service. The base-isolated frames were assessed by the variation of the selected structural response parameters such as isolator displacement, relative displacement, inter-storey drift ratio, absolute acceleration, base shear, base moment, hysteretic curve, and dissipated energy. The effectiveness of the steel buildings with HDRB was evaluated. It was shown that the seismic performance of the base-isolated structure was remarkably influenced by the isolation parameters. The higher value of the isolation period and effective damping ratio tended to increase the amount of dissipated energy associated with low post-yield stiffness ratio.
\end{abstract}

Keywords: Base isolation; Bearing property; High damping rubber bearing; Isolation parameter; Nonlinear response; Steel frame.

\section{Introduction}

Compared to traditional seismic retrofit technique that is depend on increasing of strength and ductility of the structural members by regulating their dimension and upgrading with composite materials, the base isolation technology has been increasingly gained importance and used in plenty of the buildings, especially for critical buildings, namely, hospitals, nuclear plants, stations, terminals whose functionality must continue both during and after the earthquake (Güneyisi and Deringöl, 2018). Unlike from traditional seismic retrofit technique, in base isolation system (BIS), the upper structure is decoupled from the ground and placed a flexible layer between the superstructure and its foundation thereby eliminating the seismic energy that is transmitted from ground to the structure (Skinner et al. 2003).The isolator device of BIS has low horizontal stiffness and immense vertical load carrying capacity, is placed underneath the structure so that the base-isolated structure provides greater than that of the original frames (Habieb et al. 2019). BIS can be admitted as mature passive seismic isolation technique that is developed against seismic and dynamic actions to resume the service lifespan of the civil engineering structures. For the last a few decades, BIS have been implemented not only new structures but also existing buildings in order to meet the current limit state of the seismic design codes (Clemente and Martelli, 2019). It is well known that the utilization of BIS increases the fundamental period of the base-isolated structures since the isolator provides additional damping, which hereby enables to smoothly lateral movement, but this relative displacement partially centered on the region of bearing device (Cancellara and De Angelis, 2016). In other words, the displacement and acceleration demands on the bearing interface are larger than upper storey level for base-isolated structures. The lower relative displacement and acceleration are observed in the upper part of the structure that is made possible as sustainable the serviceability of the buildings during earthquakes; thus, the destructive effect of the upcoming forces from the earthquake dissipated by means of the isolator and the whole structure members may stay in the elastic range without any damage (Cancellara and De Angelis, 2019). BIS can be classified according to interface material used in the mechanism of isolator such as sliding and laminated rubber bearings. The latter provide immense flexibility that caused large displacements and provided the vibration period of the base-isolated structures. Different types of laminated rubber bearing are 
as following: Natural rubber bearing (NRB), lead rubber bearing (LRB), and high damping rubber bearing (HDRB). Compared to the other elastomeric bearings having only damping capacity of $5 \%$, the damping capacity of HDRB reaches to $16 \%$ as well as HDRB does not need to be inserted additional lead core (Özkaya et al. 2011). Due to the fact that HDRB has higher capability of supporting large loads, it provides the recentering of the bearing shortly after the ground motions, and also keeps displacements of the structure without any maintenance or repair requirement, therefore there is growing concern for HDRB and it can be also acknowledged the most preferred laminated rubber bearing and mostly applied to highway bridges in countries such as Japan, Australia and USA (Ali and Abdel-Ghaffar, 1995). The utilization of HDRB for the seismic protection of the civil engineering structures has gained great popularity among the civil engineers in the last few decades, so there are a growing number of analytical studies and experimental applications of HDRB. For example, Bhuiyan et al. (2009) presented an analytical study which provide elasto-viscoplastic rheology model by nonlinear elasto-plastic spring to illustrate the efficiency of HDRB. Markou and Manolis (2016) studied on the mechanical models for shear behavior of HDRB, for this, five variant analytical models are developed in order to describe the stiffness hardening, energy dissipation, and shear response of HDRB under a set of strain amplitudes. The more elastoplastic elements were successfully decreased the identification error. Clemente et al. (2019) instrumented the effectiveness of HDRB in terms of accelerations by the twelve accelerometers deployed height of the buildings using the permanent seismic monitoring system. Oliveto et al. (2019) presented a set of bidirectional model, in which behavior of the isolator characterized under a wide range of strain amplitudes (e.g. 5\% and 200\%). In the study of Wei et al. (2019), the characterization of coupling effect of compressive and shear load on rate-dependent of HDRB was studied by performing monotonic shear tests under strain rates. It was observed that the increase of compressive stress resulted in the maximum shear stress of HDRB in all strain rate cases, and furthermore, stunning increment was acquired for slower strain rates. Dall'Asta and Ragni (2008) carried out nonlinear dynamic analyses of four cases produced by defining equivalent linear models of HDRB considering both transient and stationary behaviours under seven synthetic seismic excitations. In another study of Dall'Asta and Ragni (2008) the seismic response of the single degree of freedom systems were analyzed by using a rheological model adopted the contribution of constant strain and transient response of HDRB. It was showed that the dynamic responses of HDRB fairly varied by the material behaviour, seismic input level, strain rate. Alhan et al. (2016) investigated the importance of stiffening and non-stiffening characteristics of HDRB through time-history nonlinear analysis. The importance of the stiffening for HDRB gets more decisive in terms of the isolated frames subjected to near fault ground motions when their magnitude enhances and the fault distance mitigates. Dezfuli and Alam (2014) proposed a novel HDRB model, furnished with two discrete alloy wires (as supplementary damper) which utilized for a three span continuous steel girder concrete and reinforced concrete pier supported bridge were modeled. The utilization of alloy wires improved the re-centering ability of the HDRB and also the amount of dissipated energy. Tubaldi et al. (2018) proposed an advanced HDRB model which described the nonlinear behaviour of amplitude-dependent in shear of the bearing and the vertical stiffness arrangement in case of tension and compression forces. It was observed that the vertical stiffness adjustment of the isolator was estimated according to the isolated bridge. Gjorgjiev and Garevski (2013) developed a wellorganised analytical model called as "polynomial" encompassed fully simulated nonlinear stress-strain behaviour of HDRB. The currency and applicability of the polynomial model were also verified by time-history analyses. It was concluded that the nonlinear behaviour of the bearing was changed with the loading conditions. Nguyen et al. (2015) conducted an experimental test program (i.e., cyclic shear, simple relaxation, and multi-step relaxation tests) to understand the self-heating effect on the mechanical characteristics of HDRB. The remarkable result of under low and room temperatures was achieved. The effect of the reinforcement material and type of the connection systems used on the satisfactory behavior of HDRB was examined in the study of Sierra et al. (2019). It was pointed out that the isolator types including unbolted fiber reinforcement represented better behaviour. Compared to steel reinforced isolators, the fiber reinforcement isolators presented typical nonlinear response as regard greater damping ratio and horizontal stiffness. Zuniga-Cuevas and Teran-Gilmore (2013) investigated the dynamic response of 2, 4, and 8-storey base-isolated systems subjected to a set including 22 severe earthquakes whose database obtained from firm soils. It was assumed that the isolators are capable of exhibiting different damping levels, period ratio, and mass ratio. As the effective damping ratio increased, the accelerations significantly decreased especially for moderate period. Bhandari et al. (2018) performed a series of time-history nonlinear analysis for evaluating the seismic performance of 10-storey building equipped with the isolation systems subjected to bi-lateral ground motions whose fling-step, directivity, and intensity of PGA level also were 
taken into account. The numerical test results showed that the base-isolated building experienced the inelastic deformations in case of greater PGA, furthermore, it was notably mitigated with respect to the fixed-base buildings. In the study of Yang et al. (2016), a quarter scale of 3-storey steel building with HDRB was set up and conducted bilateral simulation test. It was observed that the bilateral loading produced additional deformation and shear strain in the rubber bearings due to torsional effect. In other words, the larger shear strain of $200 \%$ caused the greater coupling effect of HDRB. Alhan and Davas (2016), assessed the seismic performance of 5storey isolated frame subjected to near fault earthquakes at various fault distances with different velocity pulse periods. It was shown that the lower isolation period and greater isolator damping allowed mitigating the base displacements. It also caused inter-storey drift and storey acceleration especially for far-field earthquakes. Pant (2016), highlighted that the isolation system characterized with a range of the effective damping ratio and period changed with scaled earthquakes for 4-storey base-isolated building. It was found that the scaling has more prominent impact on the base-isolated buildings compared the characteristics of the isolation system and increasing the period of the building can be easily reduced the deformations compared the effective damping ratio. Burtscher and Dorfmann (2004) experimentally investigated the mechanical features of HDRB governed by the vertical compression and horizontal shear tests for different shear stiffness in plane direction. The test results showed that the horizontal stiffness enhances when the inclination angle of the steel plate reached to $100 \%$ in terms of shear strains, and if it keeps on increase the rubber bearing inclined to convergence. Grant et al. (2004) characterized the nonlinear damping and strain hardening behaviour of HDRB by developing a strain rate-independent model under high intensity seismic inputs. It was showed that the deformation on the bearing did not change with the characteristics of the earthquakes, while the base shear was remarkably enhanced by the higher intensity levels. Tam et al. (2015) presented a phenomenological material model to understand the nonlinear mechanical and rheological behaviour of HDRB considering "Mullins effect" that signify the particular aspect of the exerted loading tests such as relaxation, cyclic tensile, quasi-static compression test. Rahnavard and Thomas (2019) studied the nonlinear response of the rubber isolators considering the effect of the type of loadings, magnitude and direction of the exposed loads. It was shown that the stiffness of the bearing enhanced when the rubber isolator subjected to tensile axial load and multiple circular-scattered rubber cores surpassed the only one central rubber core. Given that the seismic performance of the base-isolated frames substantially based on the mechanical characteristics of the isolators, the investigation of the isolation parameters becomes quite necessary to introduce rational, economic, and engineering judgment in the seismic isolation design. Unlike from aforementioned studies, in this study, nonlinear response of the steel buildings embedded with various isolation systems of HDRB was examined in order to produce more compact intelligent isolation system by combining the mechanical characteristics of HDRB. To this aim, low (3-storey), mid (6-storey), and high-rise (9-storey) steel frames with HDRB having different design properties of the isolation period T, effective damping ratio $\beta_{\text {eff, }}$, and post-yield stiffness ratio $\lambda$ compatible with the standard of ASCE (2005) were considered. For the designing of HDRB, the values of T, $\beta$ eff, and $\lambda$ changed from 2 to $3 \mathrm{~s}, 0.05$ to 0.15 , and 3 to 6 , respectively. The examined frames were estimated through dynamic analyses by five real earthquake records, namely, 1992 Cape Mendocino, 1976 Gazl, 1978 Tabas, 1994 Northridge, and 1986 San Salvador. The comments obtained from the analyses were presented and addressed comparatively.

\section{Description of the structures and modelling assumptions}

In this parametric study, three different frames were used to examine the performance and compatibility of HDRB with the steel moment resisting frames. For this, low (3-storey), mid (6-storey), and high-rise (9-storey) fixed base frames are considered that are initially planned by Karavasilis et al. (2006) were redesigned by added HDRB. All of the storeys have same height of $3 \mathrm{~m}$. The bay width is equal to $5 \mathrm{~m}$ for all storey. The general layout of the examined frames, including section of the beams and columns are given in Figure 1. The fundamental natural periods of free vibration for low (3-storey), mid (6-storey), and high-rise (9-storey) buildings were determined as $0.73,1.31$, and $1.75 \mathrm{~s}$, respectively. The profiles of IPE and HEB are used to building of the beams and columns, respectively. The dead and live loads are only considered in the scenario of the gravity load. The amount of dead and live loads acting on the beams are assigned as 24.5 and $10 \mathrm{kN} / \mathrm{m}$, respectively. The modulus of elasticity and yield strength of steel are taken equal to $200 \mathrm{GPa}$ and $235 \mathrm{MPa}$, respectively. The post yield stiffness ratio is $\alpha=0.03$. The inherent damping ratio of the original frames is assumed to be 5\%. Moreover, comprehensive information pertained to the original frames can be find out in the 
study of Karavasilis et al. (2006). During the analyzing of the base-isolated frames, the nonlinear behavior of the structural members is assigned to plastic hinge locations where assumed to have occurred end of the columns and beams in convenient with FEMA-356 (2000). In this study, HDRB system was employed in the seismic base isolation of the case study frame structures. HDRB has similar notion of BIS and inhibit the seismic energy transferred from the ground to the structure in the event of earthquakes. HDRB consists of alternate laminated thin rubber layers and reinforced steel plates that are bonded by vulcanization (Wei et al. 2006). The isolators designed to provide horizontal post-yield elasticity and also ensure the vertical rigidity by supporting the weight of the structure. The nonlinear behaviour of HDRB is governed by the mechanical and physical characteristics of the rubber bearing (Dall'Asta and Ragni 2006; Hwang et al. 2002). Figure 1 shows the cross-sectional view and hysteretic behaviour of HDRB (Markou and Manolis 2016). HDRB has complex hysteretic response that changes with the amount of the stiffness and shear strain ratio. For example, HDRB has immense horizontal stiffness when the shear strain lower than $20 \%$, constant horizontal stiffness up to $120 \%$ of strain, at very large shear strain range (i.e., greater than $120 \%$ ) for ultimate stiffness that is restrained the occurrence of excessive shear hardening (Oh et al. 2017). The numerical modelling and analysis were performed in SAP 2000 (2011) direct integration method including P-Delta effect. Eighteen different base-isolated frame models are implemented in nonlinear frame analysis by software SAP 2000 that is enabled to describe the nonlinearity of HDRB isolator. For this, a common link element was considered as rubber isolator link element in the modeling of HDRB and it was used and assigned as a single joint element between the ground and the superstructure according to the study of Sarno et al. (2011). Both of the bearings (namely inner and outer) were separately developed for the analytical modelling of the isolated buildings in which HDRB placed between the foundation and the column of the buildings. The link property of the isolators considered as the rubber isolator link element utilized firstly by Park et al. (1986). In this way, a set of isolation systems have been modelled by means of HDRB considering different isolation properties such as isolation period $\mathrm{T}$, effective damping ratio $\beta$, and post-yield stiffness ratio $\lambda$.

An iterative design procedure applied and then the isolation parameters of HDRB were determined using following equations in accordance with Naeim and Kelly (1999). Firstly, the maximum isolator displacement was assumed and just once neglecting the yield displacement, the iteration started and continued until the assumed and obtained values were almost the same. In the iterative procedure described in ASCE (2005), the following equations were used. The assumed value of period $\mathrm{T}$ was then utilized to calculate the effective stiffness, $\mathrm{k}_{\mathrm{eff}}$;

$$
\mathrm{k}_{\mathrm{eff}}=\frac{\mathrm{W}}{\mathrm{g}} \times\left(\frac{2 \mathrm{x \pi}}{\mathrm{T}}\right)^{2}
$$

hysteresis loop (the energy dissipated per cycle), $\mathrm{W}_{\mathrm{D}}$;

$$
\mathrm{W}_{\mathrm{D}}=2 \mathrm{x} \pi \mathrm{x} \mathrm{k}_{\mathrm{eff}} \mathrm{x} \mathrm{BxD}^{2}
$$

characteristics strength, Q;

$$
\mathrm{Q}=\frac{\mathrm{W}_{\mathrm{D}}}{4\left(\mathrm{D}-\mathrm{D}_{\mathrm{y}}\right)}
$$

post-yield stiffness of the isolator, $\mathrm{k}_{2}$;

$$
\mathrm{k}_{2}=\mathrm{k}_{\mathrm{eff}}-\frac{\mathrm{Q}}{\mathrm{D}}
$$

yield displacement, $\mathrm{D}_{\mathrm{y}}$ is given by;

$$
\mathrm{D}_{\mathrm{y}}=\frac{\mathrm{Q}}{\left(\mathrm{k}_{1}-\mathrm{k}_{2}\right)}
$$

effective period, $\mathrm{T}_{\text {eff }}$ 


$$
\mathrm{T}_{\mathrm{eff}}=2 \pi \sqrt{\frac{\mathrm{W}}{\mathrm{k}_{\mathrm{eff}} \mathrm{g}}}
$$

damping reduction factor, $\mathrm{B}$;

$$
\frac{1}{B}=0.25\left(1-\ln \beta_{\text {eff }}\right)
$$

displacement of isolation, D

$$
\mathrm{D}=\frac{\mathrm{g} \cdot \mathrm{S}_{\mathrm{a}} \cdot \mathrm{T}_{\mathrm{eff}}{ }^{2}}{\mathrm{~B} \cdot 4 \pi^{2}}
$$

and yield strength, $\mathrm{F}_{\mathrm{y}}$

$$
F_{y}=Q+k_{d} \cdot D_{y}
$$

where gravitational acceleration is $\mathrm{g}, \mathrm{Q}$ is characteristic strength, $\mathrm{T}$ is target period, $\mathrm{W}$ is total weight on the isolator, $\mathrm{g}$ is gravitational force, $\mathrm{B}$ is damping reduction factor, $\mathrm{D}_{\mathrm{y}}$ is yield displacement, $\beta_{\mathrm{eff}}$ is effective damping ratio, and $S_{a}$ is spectral acceleration.

The mechanical behaviour of the rubber bearing characterized in the study of Naeim and Kelly (1999) regarding the equivalent damping ratio reaching to 0.25 . Furthermore, the post yield stiffness ratio defined as the ratio of the post-yield stiffness $\left(\mathrm{k}_{2}\right)$ to the initial stiffness $\left(\mathrm{k}_{1}\right)$, and considered as 3 and 6 . In the study of Ryan and Chopra (2004) it was suggested that the constant value of $5 \mathrm{~mm}$ for the yield displacement $\left(\mathrm{D}_{\mathrm{y}}\right)$ was taken into account rather than fixing the post-yield stiffness ratio. In this paper, as previously mentioned, a set of different base-isolated steel frame models have been generated to evaluate the isolator characteristics of HDRB that was considered as variety of frames (low, mid, and high-rise), isolation period ( $\mathrm{T}=2,2.5$, and 3 s), effective damping ratio ( $\beta_{\mathrm{eff}}=0.05,0.10$, and 0.15$)$, and post-yield stiffness ratio $(\lambda=3$ and 6$)$. In the design of HDRB, the bi-linear hysteretic behavior was regarded as shown in Figure 2(b) (Markou and Manolis 2016). Other mechanical properties of the isolators were computed by Eqs. (1)-(5) and presented in Table 1 for low-rise frame. The generated base-isolated model of isolation systems was labeled depend on their isolation period $(\mathrm{T})$, effective damping ratio $\left(\beta_{\text {eff }}\right)$, and stiffness ratio $\left(\mathrm{k}_{1} / \mathrm{k}_{2}=\lambda\right)$ as to present in the tables and figures and in the rest of the paper. For instance, T3 $\beta 15 \lambda 6$ stands for the isolation model of $\mathrm{T}=3 \mathrm{~s}, \beta_{\mathrm{eff}}=15 \%$, and $\lambda=6$.

Two-dimensional view of benchmark low (3-storey), mid (6-storey), and high-rise (9-storey) buildings with HDRB was illustrated as shown in Figure 1. In this study, a series of HDRB designed for those frames with different characterized isolation parameters. The base of each column is carried by HDRB, which is anchored to isolated foundation. The base-isolated frames analytically modelled using SAP 2000 (2011). and then nonlinear time-history analysis was performed by direct integration methods. The deformations and inertial forces were computed from the analyses result of examined frames for each earthquake. Since PGA consistently characterizes the seismic ground motion records it was accepted as an intensity measure. Five earthquake inputs were supplied using Pacific Earthquake Engineering Research Centre (PEER) (2011). data bank to perform the nonlinear time history analyses considering following intervals; $M_{w} 5.8-7.35, R_{j b} 0-3.9 \mathrm{~km}, R_{\text {rup }} 2-8.2 \mathrm{~km}, V_{\mathrm{s} 30}$ 251.2-766.8 m/s, PGA 0.59-0.80 g, PGV 62.23-118.29 cm/s, and PGD 10.01-96.80 cm. More information on the earthquake records presented in Table 2. $5 \%$ damped acceleration response spectra of the ground motions are also illustrated in Figure 3. The signals of the ground motions are scaled in accordance with ASCE 7-10 (2010). standard in which the scaled records should not be lower than the design spectrum over the period range from $0.2 \mathrm{~T}$ to $1.5 \mathrm{~T}$ where $\mathrm{T}$ is the fundamental vibration period of the building being designed.

\section{Results and Discussion}

\subsection{Isolator Displacement}


When low (3-storey), mid (6-storey), and high-rise (9-storey) frames were hit by five different earthquakes, the isolator displacements of those were determined using nonlinear time history analyses and then presented in Figures 4, 5, and 6, respectively. Moreover, in order to better investigate the effectiveness of HDRB having different design properties, the variation of average percent values of isolator displacement of each isolation system with respect to that of the case T2 $25 \lambda \lambda 3$ are given in Tables 4, 5, and 6 for low, mid, high-rise baseisolated frames, respectively. From both figures and tables, it can be obviously shown that the changing of the design characteristic of the isolator had significantly varied the isolator displacement demand of HDRB by ensuring sideway displacement of case study isolated frame structures. As post-yield stiffness ratio $\lambda$ gets lower, initial stiffness $\mathrm{k}_{1}$ become less, and utilization of $\mathrm{T}$ as 2.5 and $3 \mathrm{~s}$ produced more flexible bearing as well (see Table 1). Furthermore, the maximum isolator displacement increased in case of the isolation models consisted of the greater $\beta$ and $T$ with less $\lambda$. For example, the maximum isolator displacements of $52.50,28.47$, and $59.53 \mathrm{~cm}$ were attained in $\mathrm{T} 3 \beta 15 \lambda 3$ for low, mid, and high-rise frames subjected to Tabas, Cape, and again Tabas earthquakes, respectively. The analysis of the results indicated that $\mathrm{T}$ of $3 \mathrm{~s}$ definitely became favourable in terms of the isolator displacement independently height of the building and active earthquakes. When $\beta$ and $\lambda$ are fixed to comprehend the effect of $\mathrm{T}$ on the isolator displacement, and it was observed that the use of $\mathrm{T} 3 \beta 15 \lambda 6$ instead of T2 $\beta 15 \lambda 6$ enhanced the isolator displacement from 24.52 to $28.15 \mathrm{~cm}, 21.19$ to $27.49 \mathrm{~cm}, 18.57$ to $28.48 \mathrm{~cm}$ for low, mid, and high-rise frames subjected to Cape earthquake, respectively (see Figures 4-6). However, an adverse trend was only observed when Northridge earthquake hit low, mid, high-rise base-isolated frames and produced the maximum isolator displacement as 41.69 (T2 $\beta 5 \lambda 3), 27.45$ (T2 $\beta 15 \lambda 3)$, and $22.76 \mathrm{~cm}$ (T2 $\beta 15 \lambda 3$ ) as shown in Figures 4, 5, and 6, respectively. Moreover, the greatest enhancement on the average isolator displacement occurred as $21.7,41.6$, and $55.6 \%$ in case of the use of T3 $35 \lambda 3$ instead of T2 $255 \lambda 3$ for low, mid, and high-rise frames as shown in Tables 4-6. Similarly, the average value of the maximum isolator displacement was experienced in the isolation systems of T3 $\beta 5 \lambda 3, \mathrm{~T} 3 \beta 10 \lambda 3$, and $\mathrm{T} 3 \beta 15 \lambda 3$ as $28.19,29.22$, and $28.34 \mathrm{~cm}$, respectively. When the isolator displacement of the case study frames were evaluated considering the effect of the damping ratio it was noticed that the use of $\beta$ (namely 10 and $15 \%$ ) increased the isolator displacement in the presence of Cape, Tabas, and Salvador earthquakes, on the other hand it slightly mitigated under Northridge and Gazlı earthquakes. For instance, the increase of the effective damping ratio from 5 to $15 \%$ in the isolation system of $\mathrm{T}=3 \mathrm{~s}$ and $\lambda=6$ enhanced 3-storey base-isolated frames' isolator displacement from 11.62 to $12.05,26.27$ to $28.15 \mathrm{~cm}, 50.58$ to $52.45 \mathrm{~cm}$ under Salvador, Cape, and Tabas earthquakes, respectively as shown in Figure 4(b). However, it was reduced the isolator displacement from 21.73 to $18.39 \mathrm{~cm}, 29.56$ to $28.44 \mathrm{~cm}$ under Gazlı and Northridge earthquakes, respectively as shown in Figure 4(b). As $\beta$ of 5 reached to 15 $\%$ for mid-rise base-isolated building under Salvador, Cape, and Northridge earthquakes, the maximum isolator displacements measured in the isolation systems of $\mathrm{T} 2.5 \beta 15 \lambda 3$ as 11.9 , T3 $315 \lambda 3$ as 5.7 , and $\mathrm{T} 2 \beta 15 \lambda 3$ as $3.8 \%$, respectively. The moderate $\beta$ of $10 \%$ also satisfied the maximum isolator displacement as $60.39 \mathrm{~cm}$ (T3 $\beta 10 \lambda 3)$ under Tabas earthquake. However, an adverse trend was encountered as the maximum isolator displacement reached to $26.41 \mathrm{~cm}$ in the isolation system of T3 $35 \lambda 6$ (see Figure 5(b)). As for 9-storey base-isolated frame, in case of $\beta$ enhanced from 5 to $15 \%$, it was increased as $6.2 \%$ for T3 $\beta 15 \lambda 3,4.6 \%$ for T2 $2 \beta 15 \lambda 3$, and $6.5 \%$ for high-rise frames with T3 $\beta 15 \lambda 3$ under Tabas, Northridge, and Cape earthquakes, respectively as illustrated in

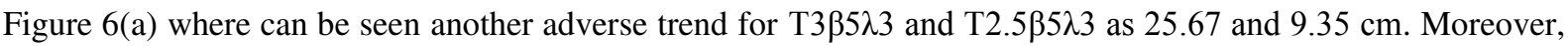
the maximum average isolator displacement of $28.34 \mathrm{~cm}$ was account for T3 $\beta 15 \lambda 3$ that has the greatest effective damping ratio as $15 \%$. The low post-yield stiffness ratio, $\lambda$ generally presented more isolator displacement than the isolation system including highest value of $\lambda$. For instance, when $\lambda$ decreased to 3 , the maximum isolator displacements of 21.89 and $25.67 \mathrm{~cm}$ occurred when low and mid-rise frames equipped with T3 $\beta 5 \lambda 3$ and hit by Gazlı earthquake as depicted in Figure 4(a), 52.5 and $59.53 \mathrm{~cm}$ obtained when low and high-rise isolated buildings equipped with T3 $\beta 15 \lambda 3$ and hit by Tabas earthquake as depicted in Figure 4(a) and 6(a), 27.45 and $22.76 \mathrm{~cm}$ acquired when mid and high-rise frames equipped with $\mathrm{T} 2 \beta 15 \lambda 3$ and then hit by Northridge earthquake as depicted in Figure 5(a) and 6(a), respectively. However, T3 $\beta 15 \lambda 6$ yielded the maximum isolator displacements as 12.05 and $28.15 \mathrm{~cm}$ when low-rise isolated frames hit by Salvador and Cape earthquakes, respectively (see Figure 4(b)). Moreover, when mid-rise hit by Gazlı earthquake the maximum isolator displacement of $26.41 \mathrm{~cm}$ was experienced as shown in Figure 5(b). As for the average maximum isolator displacement demand, mid-rise building looked more favourable than low and high-rise buildings. Compared to the isolation systems, T3 $\beta 5 \lambda 3, \mathrm{~T} 3 \beta 10 \lambda 3$, and T3 $\beta 15 \lambda 3$ presented the average value of the maximum isolator displacement as 28.19, 29.22, and $28.36 \mathrm{~cm}$ as depicted in Figure 4(b), 5(b), and 6(b), respectively. Furthermore, 
the isolation systems of T3 $\beta 5 \lambda 3, \mathrm{~T} 3 \beta 10 \lambda 3, \mathrm{~T} 3 \beta 15 \lambda 3$ that have the lowest post-yield stiffness ratio (namely $\lambda=3$ ) also succeeded the average maximum increment on the isolator displacement percentage as $21.7,42.6$, and 57.7 $\%$ versus T2 $\beta 5 \lambda 3$ for low, mid, and high-rise base-isolated frames as shown in Tables 4,5 , and 6 , respectively.

\subsection{Inter-storey Drift Ratio}

The inter-storey drift ratio can be admitted as an engineering demand parameter (EDP) to meet the limiting criteria of structural and non-structural members that are restricted in accordance with SEAOC (1999) included Operational (SP-1) as $0.5 \%$, Occupiable (SP-2) as $1.8 \%$, Life Safety (SP-3) as 3.2 \%, and Near Collapse (SP-4) as $4 \%$. Inter-storey drift could be calculated as the translational displacement of successive storey over associated storey height. The maximum inter-storey drift ratio computed in the isolated frames with the isolation systems when subjected to five earthquakes and plotted in Figures 7-9. The inter-storey drift ratio against height of the base-isolated frames with different isolation systems under Northridge earthquake was presented in Figures 10-15. Furthermore, the variation of average percent values of inter-storey drift ratios with the isolation systems according to that of T2 $\beta 5 \lambda 3$ are presented for comparison purposes. The inter-storey drift ratio of the buildings with the isolation systems evaluated whether the corresponding performance levels was satisfied or not. First, increase of $\mathrm{T}$ led to mitigate the maximum inter-storey drift ratio of the isolated frames (see Figures 79). For instance, when $\mathrm{T}$ reached to $3 \mathrm{~s}, \beta$ and $\lambda$ fixed as $5 \%$ and 3 , the maximum inter-storey drift ratios of 2.52 , 3.03 , and $2.54 \%$ (T2 $\beta 5 \lambda 3$ ) dropped to $0.69,0.99$, and $0.90 \%$ (T3 $\beta 5 \lambda 3$ ) met the limiting criteria of SP-2 for low, mid, high-rise base-isolated frames under Northridge earthquake, respectively. In addition to Figures 7-9, the influence of the isolation period to the inter-storey drift ratio can also be observed in Figures. 10-15 where the variation of the inter-storey drift versus height of the frames were presented. When low and mid-rise isolated frames equipped with the isolation systems having greater isolation period and hit by Northridge earthquake, the more uniform drift distribution, and also lower inter-storey drift ratio were produced. For example, increasing of the isolation period from 2 to $3 \mathrm{~s}$ resulted in remarkable reduction on the maximum inter-storey drift ratios of low, mid, and high-rise isolated frames, for instance, they mitigated from $2.47,2.96$, and $2.46 \%$ (T2 $\beta 5 \lambda 6$ ) to $0.64,0.96$, and $0.85 \%$ (T3 $35 \lambda 6$ ), respectively, the latter met the limiting criteria of SP-2, had uniform interstorey drift height of the storey, and similar drift ratio as $0.65 \%$ along the mid storey level of 3rd storey to 7 th storey (see Figures 14(c), 15(c))) as well. Moreover, as seen from Tables 4, 5, and 6, the greatest average inter-

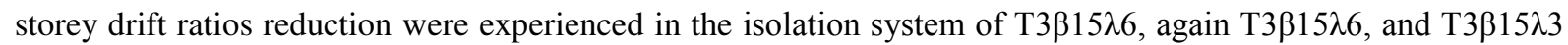
as $47.8,49.0$, and $43.7 \%$, respectively, with respect to that of T2 $\beta 5 \lambda 3$. The influence of the building heights can be observed in Figures 7-9. When low-rise frame with the isolation period of $3 \mathrm{~s}$ under Gazlı and Salvador earthquakes that was provided SP-1 level and also experienced the less inter-storey drift ratio (see Figure 7). SP1 level was also valid not only mid-rise but also high-rise isolated buildings were hit by Salvador earthquake as show in Figure 8 and 9. Secondly, the greater effective damping ratios (as 10 and $15 \%$ ) significantly produced less inter-storey drift ratios. For instance, the minimum inter-storey drift ratios of $0.42,0.55,0.54,0.20$, and 1.00

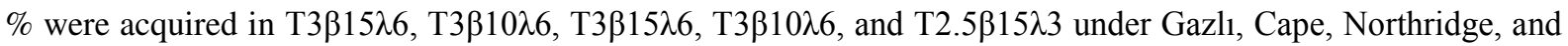
Salvador, and Tabas earthquakes (see Figure 7), respectively, which satisfied SP-1 and SP-2 for the low-rise frame. When subjected to Cape, Gazlı, Tabas, and Northridge earthquakes, the mid-rise frame with T3 $\beta 15 \lambda 6$ provided the minimum inter-storey drift ratio that is also valid for T3 $\beta 10 \lambda 3$ under Salvador earthquake as shown in Figure 8. Similarly, when high-rise base-isolated frame with T3 $\beta 15 \lambda 6$ was hit by Cape and Gazlı earthquakes the minimum inter-storey drift ratios of 1.08 and $0.87 \%$ obtained and they are in convenient with SP-2. The lowest inter-storey drift ratio of 9-storey frame with T3 $310 \lambda 6$ under Northridge and Salvador earthquakes occurred as 0.81 and $0.38 \%$ (see Figure 9) and satisfied SP-2 and SP-1, respectively. Furthermore, the changes of the inter-storey drift ratio versus buildings height plotted in Figures 10-15 where the use of the effective damping ratios of 10 and $15 \%$ not only mitigated the inter-storey drift but also provided more uniform drift distribution. For instance, when subjected to Northridge earthquake the inter-storey drift ratios at roof storey of the corresponding low, mid, high-rise base-isolated frames experienced as $0.55,0.54$, and $0.58 \%$ for the isolation system of T2 $25 \lambda \lambda 3$, respectively (see Figures 10,12 , and 14), which are decreased up to $0.51,0.51,0.53$ $\%$ for the isolation system of T2 $\beta 10 \lambda 3$, and $0.40,0.42,0.51 \%$ for the isolation system of T2 $215 \lambda 3$. The more uniform distribution of inter-storey drift was noticed in Figure 11(c), 13(b), and 14(c) for low, mid, high-rise base-isolated frames with the effective damping ratios of 15,10 , and $15 \%$, respectively. Furthermore, compared to $22 \beta 5 \lambda 3$, the average value of the maximum inter-storey drift ratio reduction of low, mid, and high-rise base- 
isolated frames with T2 $\beta 10 \lambda 3$ occurred as 7.9, 5.2, $4.5 \%$, and T2 $\beta 15 \lambda 3$ ensured as $14.4,10.6,9.2 \%$ (see Tables 4-6). Thirdly, when compared the inter-storey drift demand of the base-isolated frames considering the postyield stiffness ratio $\lambda$ (as 3,6 ), it was remarkably influenced, particularly low and mid-rise frames (see Figures 715 ). Besides, considering the increased the post-yield stiffness ratio $\lambda$ would raise demands on the inter-storey drift. In other words, if $\mathrm{T}$ and $\beta_{\text {eff }}$ kept constant, and $\lambda$ increased from 3 to 6 , the maximum inter-storey drift substantially decreased, independently building heights and ground motion characteristics. For instance, when subjected to Cape earthquake, low, mid, high-rise base-isolated frames with T2.5 $\beta 10 \lambda 3$ produced the inter-storey drift ratios as $0.81,1.44$, and $1.35 \%$, whereas $\mathrm{T} 2.5 \beta 10 \lambda 6$ introduced as $0.69,1.33$, and $1.31 \%$, respectively. In

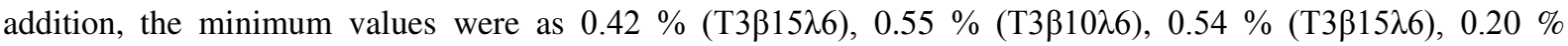
(T3 $\beta 15 \lambda 6$ ) in case of greater post-yield stiffness ratio for low-rise hit by Gazl1, Cape, Northridge, and Salvador earthquakes, respectively (see Figure 7(b)). Those also met the limiting criteria of SP-1. Similarly, when subjected to Cape, Northridge, Tabas, and Gazl earthquakes the isolation system of T3 $\beta 15 \lambda 6$ provided the lowest maximum inter-storey drift ratios of 1.02, 0.88, 2.05, and $0.85 \%$ for mid-rise frame, respectively (see Figure 8(b)). When subjected to Cape, Salvador, Northridge, and Gazlı earthquakes the lowest inter-storey drift

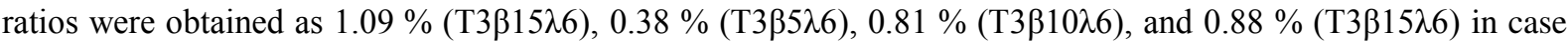
of greater post-yield stiffness ratio for high-rise frame, respectively (see Figure 9(b)), whereas the lowest

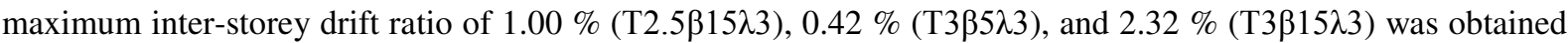
in case of the lower post-yield stiffness ratio for low, mid, high-rise base-isolated frames subjected to Tabas, Salvador, and again Tabas earthquakes as shown in Figures 7, 8, and 9, respectively. The average value of the maximum inter-storey drift ratios of low and mid-rise frames with T3 $\beta 15 \lambda 6$ computed as 0.56 and $1.05 \%$, whereas it was obtained as $1.13 \%$ for high-rise frame with T3 $315 \lambda 3$. Moreover, the use of greater post-yield stiffness ratio exhibited the more uniform inter-storey drift distribution and reduced it as well, as shown in Figures 10-15. When high-rise isolated frame with T3 $\beta 10 \lambda 6$ instead of T3 $\beta 10 \lambda 3$ that exhibited more uniform and steady inter-storey drift distribution (see between 1st to 3rd and 3rd to 5th storey level) as seen in Figures 15(b) and 14(b), respectively. Similarly, high-rise frame with T2.5 $\beta 15 \lambda 3$ and T3 $\beta 15 \lambda 3$ performed 0.38 and $0.31 \%$ inter-storey drift ratio at roof storey (see Figure 14(c)), whereas they were reduced to 0.31 and $0.24 \%$ (see Figure 15(c)), respectively.

\subsection{Relative Displacement}

The relative displacement can be found by subtracting the top storey displacement from the bearing displacement, and it can also be used as one of the most influential EDP for the seismic performance assessment. After subjecting a set of earthquakes the maximum relative displacements of the examined base-isolated frames were computed, and given in Figures 16-18. It can be proved that the relative displacements of those frames successfully eliminated when equipped with HDRB. In the design of HDRB, the utilization of the isolation period of 2.5 or $3 \mathrm{~s}$ and post-yield stiffness ratio of 3 developed characterized isolator had less stiffness (see Table 1) and thereafter the base-isolated buildings can be smoothly moved and the relative displacements of the buildings mitigated. When increase the isolation period the relative displacements considerably mitigated. For instance, when subjected to Cape, Gazlı, Tabas, Northridge, and Salvador earthquakes, the lowest relative displacements were obtained as $3.33,2.58,5.71,3.42$, and $1.18 \mathrm{~cm}$ in 3 -storey frame with T3 $\beta 5 \lambda 6, \mathrm{~T} 33 \beta 15 \lambda 6$, $\mathrm{T} 3315 \lambda 3$, T3 $\beta 15 \lambda 6$, and again T3 $\beta 15 \lambda 6$ (see Figure 16), respectively. Moreover, the lowest average value

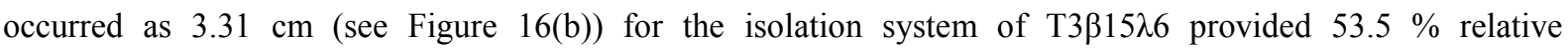
displacement reduction with respect to T2 $\beta 5 \lambda 3$ (see Table 3). When considered 6-storey frame, the lowest relative displacement of $7.45,6.33,16.86,7.21$, and $6.50 \mathrm{~cm}$ were actualized for the isolation systems of

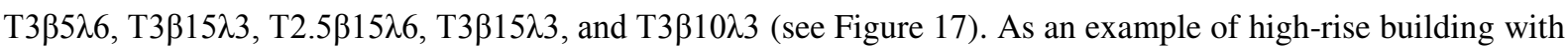

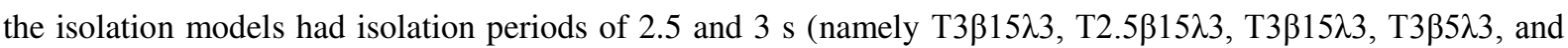
T3 $315 \lambda 3$ ) provided the lowest relative displacements as $8.79,10.75,26.46,11.65$, and $5.45 \mathrm{~cm}$ for high-rise building, respectively. Furthermore, the lowest average value of 9.15 and $15.71 \mathrm{~cm}$ corresponding to reduction

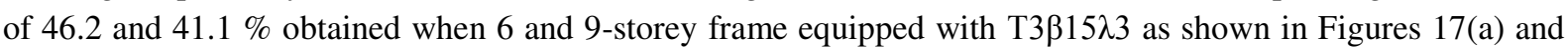
18 (a), respectively. It was clearly observed that the maximum relative displacement decreased and also behaved more uniform distribution over the storey height in the case of HDRB designed by the greater isolation period as shown in Figures 19-24. When it enhanced from 2 to $3 \mathrm{~s}$ and the others are fixed (namely, $\beta=5 \%$ and $\lambda=6$ ) the relative displacement of 7.42 dropped to $1.93 \mathrm{~cm}$ at 1 st storey of low-rise building, and also resulted in the 
greatest relative displacement reduction of $74.0 \%$ (see Figure 20(a)). Instead of T2 $\beta 10 \lambda 3$, the utilization of T3 $\beta 10 \lambda 3$ provided the greatest relative displacement reduction as $67.7 \%$ at roof storey of mid-rise building (see Figure 21(b)). The most uniform tendency was testified when 9-storey frame with T3 $\beta 5 \lambda 6$ hit by Northridge earthquake, and also it presented the greatest relative displacement reduction as $67.0 \%$ compared to T2 $25 \lambda 6$ (see Figure 24(a)). The variation of the effective damping ratio fluctuated the relative displacement demand of the examined frames. The performance of the isolated frames with greatest effective damping ratio was found to be superior to that of the low and moderate effective damping ratio. The isolation system of $T 3 \beta 15 \lambda 3$ succeeded the lowest relative displacements of $5.71 \mathrm{~cm}$ in the event of 3-storey frame hit by Cape earthquake (see Figure 16(a)), it was as 7.21 and $6.33 \mathrm{~cm}$ for mid-rise building hit by Northridge and Gazlı earthquakes (see Figure 17(a)), 5.45, 8.79, and $26.46 \mathrm{~cm}$ for high-rise building under Salvador, Cape, and Tabas earthquakes (see Figure 18(a)), respectively. Similarly, when subjected to Northridge, Salvador, and Gazlı earthquakes, the lowest maximum relative displacements of $3.42,1.18$, and $2.58 \mathrm{~cm}$ were witnessed in low-rise frame with T3 $\beta 15 \lambda 6$, respectively, (see Figure 16(b)). However, an example of exception testified when low and mid-rise frames with T3 $\beta 15 \lambda 6$ hit by Cape earthquake, it was occurred as 3.33 and $7.45 \mathrm{~cm}$, respectively. As for high-rise frame with T3 $\beta 5 \lambda 3$, it was as $11.65 \mathrm{~cm}$ when subjected to Northridge earthquake. Furthermore, the utilization of the moderate and greatest value of $\beta$ enabled to mitigate the relative displacement and provide more uniform relative displacement distribution with storey level as well. For instance, when $\beta$ of 5 reached to 10 , and then $15 \%$, keep the other isolation parameters constant (namely, $\mathrm{T}=2 \mathrm{~s}$ and $\lambda=6$ ), the maximum relative displacement at roof storey mitigated from 12.75 to $11.28 \mathrm{~cm}$, and then $7.05 \mathrm{~cm}$ in low-rise frame hit by Northridge earthquake, decreased from 25.59 to 24.21 , and then $22.43 \mathrm{~cm}$ in mid-rise frame, furthermore, it was also decreased from 24.89 to 23.81 , and then $22.86 \mathrm{~cm}$ in high-rise frame (see Figures 20, 22, and 24), respectively. Moreover, the effectiveness of the damping ratio in the design of HDRB can be also followed by Tables 4,5 , and 6 , in which the variation of the average relative displacement compared with T2 $\beta 5 \lambda 3$ in percentage. It can be seen that lowrise frame with $\mathrm{T} 3 \beta 5 \lambda 3, \mathrm{~T} 3 \beta 10 \lambda 3$, and $\mathrm{T} 3 \beta 15 \lambda 3$ significantly reduced the relative displacement as $47.8,50.2$, and $51.7 \%$ (see Table 3) with respect to T2 $25 \lambda 3$. It occurred as 37.6, 42.1, 46.2 \% (see Table 4) for mid-rise frame and 36.8, 37.2, and $41.1 \%$ (see Table 5) for high-rise frame. A set of $\lambda$ (as 3,6) had been proposed to characterize the response of the examined frames with HDRB. As can be seen from Figures 16-24, the maximum relative displacement was significantly changed by $\lambda$. Compared to the others, T3 $\beta 15 \lambda 6$ including $\lambda$ of 6 provided the lowest relative displacements as 1.18, 3.42, and $2.58 \mathrm{~cm}$ for low-rise hit by Salvador, Northridge, and Gazlı earthquakes (see Figure 16(b)), while T3 $\beta 15 \lambda 3$ included $\lambda$ of 3 produced the lowest relative displacement as 7.21 and $6.33 \mathrm{~cm}$ for mid-rise frame subjected to Northridge and Gazlı earthquakes (see Figure 17(a)), and that was as 36.46, 8.79, and $5.45 \mathrm{~cm}$ for high-rise hit by Tabas, Cape, and Salvador earthquakes (see Figure 18(a)), respectively. Similarly, the effectiveness of the greater post-yield stiffness ratio on 3-storey isolated frame can be also monitored in Table 3 where the average relative displacement reduction was recorded

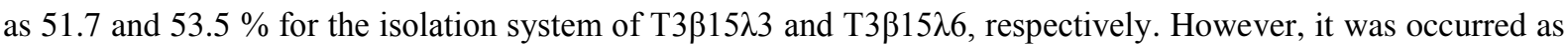
46.2 and $43.1 \%$ for mid-rise frame (see Table 4), and 41.1 and $39.1 \%$ for high-rise frame (see Table 5), respectively. The use of greater $\lambda$ proved the relative displacement reduction for low-rise frame and assisted to ensure more uniform relative displacement distribution as shown in Figures 19(c) and 20(c). Conversely, the lower post-yield stiffness ratio mitigated the relative displacement and also enabled relative displacement to behave more uniform distribution over the height of mid and high-rise frames as shown in Figures 21-24.

\subsection{Absolute Acceleration}

The examined frames with HDRB subjected to a set of earthquakes and then the maximum absolute accelerations computed and plotted in Figures 25-27. Furthermore, the change of one storey to another is described in Figures 28-33. Firstly, it was generally provided the lowest absolute accelerations when 2.5 and $3 \mathrm{~s}$ utilized as the isolation period independently height of the buildings and active earthquakes as well. When subjected to Northridge and Salvador earthquakes, the lowest maximum absolute accelerations of 1.66 and 1.33 $\mathrm{m} / \mathrm{s}^{2}$ for T3 $\beta 15 \lambda 3$ were achieved (see Figure 25(a)). T3 $\beta 10 \lambda 6$ presented as 1.65 and $2.29 \mathrm{~m} / \mathrm{s}^{2}$ under Gazlı and Tabas earthquakes (see Figure 25(b)) for low-rise frame, respectively. It was reported as 1.85 and $2.55 \mathrm{~m} / \mathrm{s}^{2}$ for

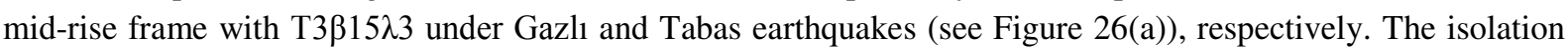
system of T3 $\beta 10 \lambda 3$ and T3 $35 \lambda 3$ also introduced the lowest absolute acceleration. The former produced as 2.29 $\mathrm{m} / \mathrm{s}^{2}$ under Northridge earthquake, the latter obtained as 2.3 and $2.78 \mathrm{~m} / \mathrm{s}^{2}$ when mid-rise frame hit by Cape and 
Salvador earthquakes (see Figure 26(a)). When subjected to Cape, Gazl1, again Gazl1, Northridge, and Salvador earthquakes, the lowest maximum absolute accelerations occurred as $2.47,2.08,3.39,2.73$, and $2.36 \mathrm{~m} / \mathrm{s}^{2}$ for

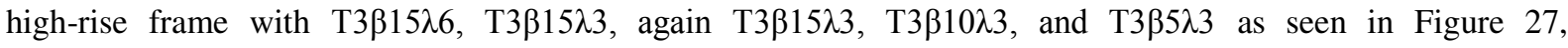
respectively. The use of the isolation periods of 2.5 and $3 \mathrm{~s}$ not only decreased the absolute acceleration but also was capable of uniform absolute acceleration distribution as shown in Figures 29(c), 30(a and b), 33 (b and c) where the absolute acceleration stayed constant at low storey level. Tables 4-6 proved the reduction of the absolute acceleration when utilized moderate and high periods. For low, mid, high-rise base-isolated frames with $\mathrm{T} 3 \beta 5 \lambda 3$, T3 $315 \lambda 3$, and $\mathrm{T} 3 \beta 5 \lambda 6$ introduced the greatest value of average absolute acceleration reduction as 37.8 , 36.4 , and $41.1 \%$, respectively. Secondly, less effective damping ratio led to mitigation of the maximum absolute acceleration especially mid and high-rise frames. For example, it can be smoothly observed in Figures 25(a), 26(b), 27(b), described the maximum absolute accelerations of low, mid, high-rise isolated buildings hit by Cape, Salvador, and again Salvador earthquakes, respectively. On the other hand, when $\beta$ reached to greatest value of $15 \%$, T3 $315 \lambda 3$ yielded the lowest maximum absolute accelerations as 1.66 and $1.33 \mathrm{~m} / \mathrm{s}^{2}$ for low-rise frame hit by Northridge and Salvador earthquakes (see Figure 25(a)), 1.85, $2.55 \mathrm{~m} / \mathrm{s}^{2}$ for mid-rise (see Figure 26(a)), 2.08 and $3.39 \mathrm{~m} / \mathrm{s}^{2}$ for high-rise frame hit by Gazlı and Tabas earthquakes (see Figure 27(a)), respectively. Although T3 $\beta 10 \lambda 3$ had moderate effective damping ratio, as seen in Figures 26(a) and 27(a), when mid and high-rise frames subjected to Northridge earthquake the lowest absolute acceleration obtained as 2.29 and $2.73 \mathrm{~m} / \mathrm{s}^{2}$, respectively. However, an adverse trend, it was as $1.48 \mathrm{~m} / \mathrm{s}^{2}$ when low-rise frame equipped with T3 $\beta 5 \lambda 3$ and hit by Gazlı earthquake, 2.3 and $2.78 \mathrm{~m} / \mathrm{s}^{2}$ for mid-rise hit by Cape and Salvador earthquakes, respectively, and $2.36 \mathrm{~m} / \mathrm{s}^{2}$ for high-rise frame hit by Salvador earthquake. The utilization of $\beta$ of 10 and $15 \%$ enabled to absolute acceleration mitigation as shown in Figure 25. In other words, when increased $\beta$ up to 10 and last $15 \%$ and kept others constant (namely $\mathrm{T}=2 \mathrm{~s}$ and $\lambda=3$ ), it was observed that the roof storey absolute acceleration reduced from 4.10 to 3.92 and $3.49 \mathrm{~m} / \mathrm{s}^{2}$, respectively. The greatest improvements in the absolute acceleration reduction and the most uniform absolute acceleration distributions over the height of the structure were witnessed when Figures 29(a) and 29(b) compared with 29(c). Thirdly, when used less post-yield stiffness ratio in the design of HDRB that mitigated the maximum absolute acceleration. For instance, when $T$ and $\beta$ regarded as $2 \mathrm{~s}$ and $10 \%$, respectively, and the post-yield stiffness ratio decreased from 6 to 3 , the maximum absolute acceleration was diminished from 4.20 to $3.92,3.77$ to $3.59,3.87$ to $3.72 \mathrm{~m} / \mathrm{s}^{2}$ for low, mid, and highrise frames hit by Northridge earthquake, respectively. Furthermore, low-rise frame with T3 $\beta 5 \lambda 3$ had less postyield stiffness ratio provided the lowest absolute acceleration as $1.48 \mathrm{~m} / \mathrm{s}^{2}$ under Gazlı earthquake (see Figure 25(a)), it was as 2.30 and $2.78 \mathrm{~m} / \mathrm{s}^{2}$ for mid-rise frame hit by Cape and Salvador earthquakes (see Figure 26(a)), respectively; when subjected to Salvador earthquake it was as $2.36 \mathrm{~m} / \mathrm{s}^{2}$ for high-rise frame (see Figure 27(a)). However, an exception for the effectiveness of the greater post-yield stiffness ratio obtained the lowest absolute acceleration as 1.65 and $2.29 \mathrm{~m} / \mathrm{s}^{2}$ in case of Cape and Tabas earthquakes that hit the low-rise frame with T3 $310 \lambda 6$ (see Figure 25(b)), respectively. Similarly, it occurred as $2.47 \mathrm{~m} / \mathrm{s}^{2}$ in case of Cape earthquake hit highrise frame with T3 $\beta 15 \lambda 6$ (see Figure 27(b)). As shown in Figures 28-29, the reduction of the post-yield stiffness made the absolute acceleration distribution more uniform for low-rise frame.

\subsection{Base Shear}

The effectiveness of using HDRB having different design properties was assessed through nonlinear analyses in which low, mid, and high-rise buildings hit by a series of earthquakes, and then the base shear demands of those were computed. The base shear demands of those were divided by corresponding total weights of 1290, 2540, and $3686 \mathrm{kN}$ to compare the significance of the isolation systems of HDRB regarding the earthquake characteristics. The base shear ratios were in the range of 0.045-0.354 in all frames and depicted in Figures 3739 where can be seen the use of HDRB substantially mitigated the base shear demand, depending on the number of storey of the structures. Compared to the lower isolation period, the greatest isolation period remarkably mitigated the base shear, irrespective of the earthquake characteristics. For instance, when Gazlı and Northridge earthquakes hit the low-rise frame with T3 $\beta 15 \lambda 6$ the lowest normalized base shears of 0.085 and 0.108 were obtained as shown in Figures 34(b). Similarly, when subjected to Cape, Gazlı and Northridge earthquakes, it was as $0.114,0.098$, and 0.099 for mid-rise frame (see Figure 35(b)), 0.102, 0.084, and 0.081 for high-rise frame (see Figure 36(b)), respectively. The utilization of $\mathrm{T}$ as 2.5 and $3 \mathrm{~s}$ caused notable reduction especially for low rise buildings. For example, as T increased 2.5 and then $3 \mathrm{~s}$, the reductions of the average base shear were occurred 
as 26.1 and $49.5 \%$ for low-rise frame, 17.8 and $31.6 \%$ for mid-rise frame, and 17.3 and $26.5 \%$ for high-rise frame as shown in Tables 4, 5, and 6, respectively. Furthermore, the use of $\beta$ as 10 and $15 \%$ reduced the base shear demand. For instance, when increased $\beta$ from 5 to $10 \%$ in the isolation of low, mid, and high-rise frames with T2 $\beta 5 \lambda 3$ and hit by Cape earthquake, the normalized base shear mitigated from 0.215 to $0.210,0.209$ to 0.201 , and 0.187 to 0.183 , respectively. The average base shear reductions in connection with the effective damping ratio also testified in Tables 4, 5, and 6 where the greatest base shear reductions occurred as 47.6, 36.9, and $37.5 \%$ in the isolation system of T3 $\beta 15 \lambda 6$, respectively. Furthermore, when Cape and Salvador earthquakes hit low and high-rise buildings equipped with moderate $\beta$ of $10 \%$ (namely T3 $\beta 10 \lambda 6$ ), the lowest normalized base shear witnessed as 0.106 and 0.048 (see Figures 34(b) and 36(b)), respectively. The greater post-yield stiffness ratio of 6 was more decisive on the base shear demand as shown in Figures 34-36. For instance, when subjected to Northridge earthquake the normalized base shear of low, mid, and high-rise frames with T3 $\beta 15 \lambda 3$ introduced as $0.064,0.060$, and 0.058 while $T 3 \beta 15 \lambda 6$ case reduced it up to $0.060,0.052$, and 0.052 , the corresponding reduction percentages occurred as $6.3,13.3$, and $10.34 \%$, respectively. Similar trend can also be testified in Tables 4-6 where the average base shear reductions of the isolation systems are given in comparision with T2 $\beta 5 \lambda 3$. The use of $\lambda$ as 6 in the isolation models such as T3 $\beta 15 \lambda 6$ reduced the average base shear as 47.6, 36.9 , and $37.5 \%$ for low, mid, and high-rise frames, respectively.

\subsection{Base Moment}

The base moment demands of the examined structures are plotted in Figures 37-39. Moreover, the average base moment variations are given in Tables 4-6. It was evidently proved that the base moments of the frames with HDRB fluctuated depending on the isolation parameters. HDRB sufficiently reduced the base moment in case of

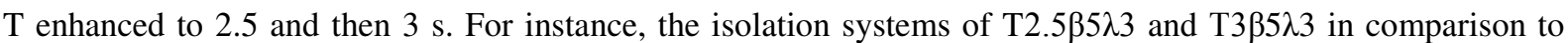
that of T2 $25 \lambda \lambda 3$ significantly mitigated the average base moments as 25.5 and $42.5 \%$ in low-rise frame (see Table 3), 19.3 and $32.1 \%$ in mid-rise frame (see Table 4), 17.2 and $27.8 \%$ in high-rise frame (see Table 5), respectively. Furthermore, when Tabas and Northridge earthquakes hit low and mid-rise frames with T3 $\beta 15 \lambda 3$ case, the minimum base moments of former computed as 1513 and $957.8 \mathrm{kNm}$ (see Figure 37(a)), the latter occurred as 5632 and $3337 \mathrm{kNm}$ (see Figure 38(a)), respectively. The minimum base moment of low-rise frame was testified as $757 \mathrm{kNm}$ in case of T3 $315 \lambda 6$ under Gazlı earthquake (see Figure 37(b)). Similarly, when midrise frame hit by Cape and Gazlı earthquakes, it was as 3478 and $2837 \mathrm{kNm}$ (see Figure 38(b)), $6445 \mathrm{kNm}$ in case of high-rise frame subjected to Cape earthquake (see Figure 39(b)), respectively. It was mostly more prone to produce less base moment demand when selected $\beta$ as 10 and $15 \%$ in the design of HDRB. When $\beta$ of $5 \%$ increased to 10 and then $15 \%$ (assume $\mathrm{T}$ and $\lambda$ are 2 and 3), and subjected to Northridge earthquake, the base moment reduced from 2812 to 2612 and $2276 \mathrm{kNm}$ for low-rise frame, 7816 to 7467 and $6605 \mathrm{kNm}$ for mid-rise frame, 15320 to 14900 and $14160 \mathrm{kNm}$ for high-rise frame as shown in Figures 37(a), 38(a), and 39(a), respectively. In addition, the greatest avereage base moment reductions recorded as $45.4,36.6$, and $37.5 \%$ when

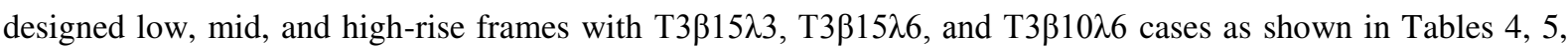
and 6, respectively. The influence of $\lambda$ on the base moment demand could be monitored through Figures 37-39 where proved the base moment not only changed with $\lambda$ but also building heights and earthquake characteristics. Compared to T2 $\beta 5 \lambda 3,2 \beta 5 \lambda 6$ enabled to reduce the maximum base moment from 1821 to 1722,1048 to 1030 , 2176 to 2126 , and 2812 to $2807 \mathrm{kNm}$ in case of low-rise frame hit by Cape, Gazlı, Tabas, and Northridge earthquakes, respectively. Similarly, it diminished dramatically from 6000 to 5824,3973 to 3752,7816 to 7695 , and 4394 to $4211 \mathrm{kNm}$ when mid-rise frame equipped with T2 $55 \lambda 6$ and then hit by Cape, Gazl1, Northridge, and Salvador earthquakes, respectively. When high-rise building hit by Cape, Tabas, Northridge, and Salvador earthquakes, it also reduced from 14520 to 14100,14860 to 14690,15320 to 15200 , and 5579 to $5407 \mathrm{kNm}$, respectively. It can be said that $\lambda$ was less decisive than the $T$ and $\beta$ as shown in Figures 37-39.

\subsection{Typical Hysteretic Curves and Energy Dissipation}

When subjected to Gazlı earthquake the hysteretic curves of low, mid, and high-rise frames with eighteen various HDRB obtained and given in Figures 40, 41, and 42, respectively. Those hysteretic curves were compatible with the typical bi-linear hysteretic force-displacement relationship (see Figure 2(b)) (Markou and Manolis 2016). The isolation parameters significantly influenced the hysteretic characteristics of low, mid, and 
high-rise frames depending on the characteristics of ground motions. The utilization of the greater isolation period not only enlarged the area of the curves and also changed those behaviours. When $\beta$ and $\lambda$ were fixed, the minimum and maximum oblique hysteretic curves were plotted for $\mathrm{T}$ of 2 and $3 \mathrm{~s}$, respectively. The hysteretic curves including moderate value of $\mathrm{T}$ (namely, $2.5 \mathrm{~s}$ ) located between them (see Figures 40-42). Furthermore, when HDRB designed with $\mathrm{T}=3 \mathrm{~s}$ and $\beta=5 \%$, T3 $\beta 5 \lambda 3$ was remarkably enlarged the hysteretic curves reached to the strains of $0.206 \mathrm{~m}, 0.240$, and $0.245 \mathrm{~m}$ corresponded to the forces of $43.12,90.91$, and $142.10 \mathrm{kN}$ as shown in Figures 40(a), 41(a), and 42(a) for low, mid, and high-rise buildings hit by Gazlı earthquake, respectively. The less $\beta$ tended to be depicted the larger hysteretic curve independently height of the buildings in case of $\mathrm{T}$ and $\lambda$ were fixed. Similarly, the larger hysteretic curves obtained when the examined isolated frames

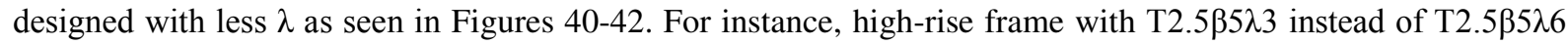
that was increased the displacement and force of the hysteretic curve from 0.185 to $0.190 \mathrm{~m}$ and 155.74 to $160.74 \mathrm{kN}$ as shown in Figure 42. In addition, the reduction of $\lambda$ made the hysteretic curve described linear behaviour while the shape of the hysteretic curve seemed to have been angular in case of $\lambda$ enhanced to 6 . For low, mid, and high-rise frames equipped with HDRB and hit by Gazlı earthquake, the amount of the dissipated energy could be computed by Eqn. 10 (FEMA P-750 2009), and given in Table 6.

$$
\mathrm{E}_{\text {loop }}=4\left(\mathrm{D}_{\max } \mathrm{F}_{\mathrm{y}}-\mathrm{F}_{\max } \mathrm{D}_{\mathrm{y}} \quad\right)
$$

where $E_{\text {loop }}, D_{\max }, F_{y}, F_{\max }$, and $D_{y}$ are the amount of the dissipated energy, maximum displacement, yield force, maximum force, and yield displacement of the isolator, respectively.

The utilization of both greater $T$ and $\beta$ with less $\lambda$ was necessary to obtain more and more energy dissipation as

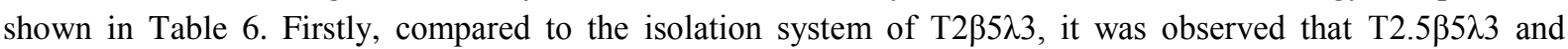
T3 $35 \lambda 3$ cases increased the dissipated energy as 28.5 and $43.8 \%$ for low-rise frame, 23.8 and $54.2 \%$ for midrise frame, and 23.4 and $32.7 \%$ for high-rise frame, respectively. The influence of $\beta$ on the amount of the dissipated energy can be evaluated by Table 6. For instance, when low, mid, and high-rise frames hit by Gazlı earthquake T3 $315 \lambda 3$ ensured the maximum dissipated energies as $7.09,17.40$, and $26.20 \mathrm{~kJ}$, respectively. The use of less $\lambda$ let the dissipated energy to be increased as shown in Table 6 .

\section{Conclusions}

The following conclusions can be drawn from in this study;

1) The nonlinear response of low, mid, and high-rise frames with HDRB was differentiated through the isolation parameters (namely T, $\beta$, and $\lambda$ ), building heights, and characteristics of the earthquakes.

2) The isolation system composed of the greater $\mathrm{T}$ and $\beta$ with $\lambda$ (i.e., T3 $\beta 15 \lambda 3$ and $\mathrm{T} 3 \beta 10 \lambda 3$ ) was more prone to produce the greater isolator displacement with respect to other isolation models. For instance, it was as 28.19,

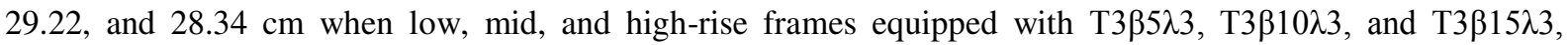
respectively.

3) The isolation system of T3 $\beta 15 \lambda 6$ provided the lowest inter-storey drift ratio and also behaved more uniform distribution over the building height. The lowest value of the average inter-storey drift ratios of 0.55 and $1.05 \%$ verified the SP-1 and SP-2 performance levels for low and mid-rise frames with T3 $\beta 15 \lambda 6$ case while it was experienced as $1.13 \%$ with the isolation system of T3 $\beta 15 \lambda 3$ satisfied the performance level of SP- 2 for high-rise frame.

4) The utilization of the greatest $T, \beta$, and $\lambda$ significantly mitigated the maximum relative displacement, but the relative displacement changed with the building heights and characteristics of the ground motions as well. T3 $\beta 15 \lambda 6$ gave the most uniform relative displacement distribution over building height. The lowest value of the average relative displacement proved as $3.31 \mathrm{~cm}$ while it was found as 9.15 and $15.71 \mathrm{~cm}$ for mid and high-rise frames with $\mathrm{T} 3 \beta 15 \lambda 3$, respectively. 
5) The greatest isolation period was decisive and influential on the reduction of the absolute acceleration of the examined buildings under earthquakes whereas it was not valid for $\beta$ and $\lambda$. The low, mid, and high-rise frames

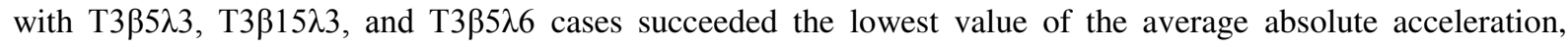
respectively. Moreover, use of greater isolation parameters ensured the more uniform absolute acceleration distribution over the height of the structures.

6) The variation of the isolation parameters changed the normalized base shear and base moment demands of low, mid, and high-rise frames. For instance, the lowest normalized base shear of $0.108,0.099$, and 0.081 were obtained when low, mid, and high-rise frames with T3 $\beta 15 \lambda 6$ hit by Northridge earthquakes. In addition, low-rise

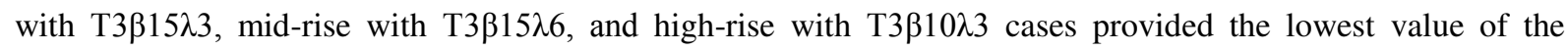
average base moment.

7) The use of appropriate HDRB models noticeably provided not only maximum energy dissipation but also the largest hysteretic curves; furthermore aforementioned isolation system was liable to hysteretic curve of HDRB.

8) The greater values of isolation parameters mostly assumed to be more essential in the event of the seismic performance of the examined frames was evaluated considering the displacements and drifts

\section{Compliance with Ethical Standards:}

Funding: No funding was received.

Conflict of Interest: The authors declare that they have no conflict of interest.

\section{References}

Alhan C, Davas SÖ (2016) Performance limits of seismically isolated buildings under near-field earthquakes. Engineering Structures 116:83-94.

Alhan C, Gazi H, Kurtuluş H (2016) Significance of stiffening of high damping rubber bearings on the response of base-isolated buildings under near-fault earthquakes. Mechanical Systems and Signal Processing 79:297-313.

Ali H-E, Abdel-Ghaffar AM (1995) Modelling the nonlinear seismic behaviour of cable-stayed bridges with passive control bearings. Computers \& Structures 54(3):461-492.

American Society of Civil Engineers ASCE (2010) Minimum design loads for buildings and other structures. ASCE/SEI 7-10, Reston, VA.

ASCE 7-05 (2005) Minimum design loads for buildings and other structures. American Society of Civil Engineers, Reston, Virginia.

Bhandari M, Bharti SD, Shrimali MK, Datta TK (2018) The numerical study of base-isolated buildings under near-field and far-field earthquakes. Journal of Earthquake Engineering 22(6):989-1007.

Bhuiyan AR, Okui Y, Mitamura H, Imai T (2009) A rheology model of high damping rubber bearings for seismic analysis: Identification of nonlinear viscosity. International Journal of Solids and Structures 46(78):1778-1792.

Burtscher SL, Dorfmann A (2004) Compression and shear tests of anisotropic high damping rubber bearings. Engineering Structures 26:1979-1991.

Cancellara D, De Angelis F (2019) Dynamic assessment of base isolation systems for irregular in plan structures response spectrum analysis vs nonlinear analysis. Composite Structures 215:98-115.

Cancellara D, De Angelis F (2016) Nonlinear dynamic analysis for multi-storey RC structures with hybrid base isolation systems in presence of bi-directional ground motions. Composite Structures 154:464-492.

Clemente P, Bongiovanni G, Buffarini G, Saitta F, Castellano MG, Scafati F (2019) Effectiveness of HDRB isolation systems under low energy earthquakes. Soil Dynamics and Earthquake Engineering 118:207-220.

Clemente P, Martelli A (2019) Seismically isolated buildings in Italy: state-of-the-art review and applications. Soil Dynamics and Earthquake Engineering 119:471-487.

Computers and Structures, (CSI) Inc (2011) SAP 2000 Advanced 14.0.0 Software. Structural Analysis Program, Berkeley, California.

Dall'Asta A, Ragni L (2006) Experimental tests and analytical model of high damping rubber dissipating devices. Engineering Structures 28:1874-1884.

Dall'Asta A, Ragni L (2008) Dynamic systems with high damping rubber: nonlinear behaviour and linear approximation. Earthquake Engineering and Structural Dynamics 37(13):1511-2526.

Dall'Asta A and Ragni L (2008) Nonlinear behavior of dynamic systems with high damping rubber devices. Engineering Structures. 30:3610-3618.

Dezfuli FH, Alam MS (2014) Performance-based assessment and design of FRP-based high damping rubber bearing incorporated with shape memory alloy wires. Engineering Structures 61:166-183. 
Federal Emergency Management Agency, FEMA (2000) Prestandard and commentary for the seismic rehabilitation of buildings. FEMA-356. Washington, D. C.

FEMA (2009) NEHRP recommended seismic provisions for new buildings and other structures. FEMA P-750, Washington, D.C.

Gjorgjiev I, Garevski MA (2013) Polynomial analytical model of rubber bearings based on series of tests. Engineering Structures 56:600-609.

Grant DN, Fenves GL, Whittaker AS (2004) Bidirectional Modelling Of High-Damping Rubber Bearings. Journal of Earthquake Engineering 8(1):161-185.

Güneyisi EM, Deringöl AH (2018) Seismic response of friction damped and base-isolated frames considering serviceability limit state. Journal of Constructional Steel Research 148:639-657.

Habieb AB, Valente M, Milani G (2019) Effectiveness of different base isolation systems for seismic protection: numerical insights into an existing masonry bell tower. Soil Dynamics and Earthquake Engineering 125:105732. Hwang JS, Wu JD, Pan TC, Yang GA (2002) Mathematical hysteretic model for elastomeric isolation bearings. Earthquake Engineering and Structural Dynamics 31:771-789.

Karavasilis TL, Bazeos N, Beskos DE (2006) Maximum displacement profiles for the performance based seismic design of plane steel moment resisting frames. Engineering Structures 28(1):9-22.

Madera Sierra IE, Losanno D, Strano S, Marulanda J, Thomson P (2019) Development and experimental behavior of HDR seismic isolators for low-rise residential buildings. Engineering Structures 183:894-906.

Markou AA, Manolis GD (2016) Mechanical models for shear behavior in high damping rubber bearings. Soil Dynamics and Earthquake Engineering 90:221-226.

Naeim F, Kelly JM (1999) Design of seismic isolated structures, from theory to practice. John Wiley \& Sons, New York, NY, USA.

Nguyen DA, Dang J, Okui Y, Amin AFMS, Okada S, Imai T (2015) An improved rheology model for the description of the rate-dependent cyclic behavior of high damping rubber bearings. Soil Dynamics and Earthquake Engineering 77:416-431.

Oh J, Kim JH, Han SC (2017) An experimental study on the shear property dependency of high-damping rubber bearings. Journal of Vibroengineering 19(8):6208-6221.

Oliveto ND, Markou AA, Anthanasiou A (2006) Modeling of high damping rubber bearings under bidirectional shear loading. Soil Dynamics and Earthquake Engineering 118:179-190.

Ozkaya C, Akyuz U, Caner A, Dicleli M, Pınarbası S (2011) Development of a new rubber seismic isolator: ball rubber bearing (BRB). Earthquake Engineering and Structural Dynamics 40(12):1337-1352.

Pant DR (2017) Influence of scaling of different types of ground motions on analysis of code-compliant fourstory reinforced concrete buildings isolated with elastomeric bearings. Engineering Structures 135:53-67.

Park YJ, Wen YK, Ang AHS (1986) Random Vibration of Hysteretic Systems under Bi-Directional Ground Motions. Earthquake Engineering and Structural Dynamics 14:543-557.

PEER (2011). User's manual for the PEER ground motion database application. The Pacific Earthquake Engineering Research Center, University of California, Berkeley.

Rahnavard R, Thomas RJ (2019) Numerical evaluation of steel-rubber isolator with single and multiple rubber cores. Engineering Structures 198:109532.

Ryan KL, Chopra AK (2004) Estimating the seismic displacement of friction pendulum isolators based on nonlinear response history analysis. Earthquake Engineering and Structural Dynamics, 33(3):359-373.

Sarno LD, Chioccarelli E and Cosenza E (2011) Seismic response analysis of an irregular base isolated building. Bulletin of Earthquake Engineering 9:1673-1702.

SEAOC (1999) Seismology committee recommended lateral force requirements and commentary. Structural Engineers Association of California, Sacramento, CA.

Skinner RI, Robinson WH, McVerry GH (2003) An introduction to seismic isolation. John Wiley Sons, New York.

Tam QN, Violaine T, Fond C (2015) The modelling of nonlinear rheological behaviour and Mullins efect in High Damping Rubber. International Journal of Solids and Structures 75-76:235-246.

Tubaldi E, Mitoulis SA, Ahmadi H (2018) Modeling of high damping rubber bearings under bidirectional shear loading. Soil Dynamics and Earthquake Engineering 104:329-345.

Wei W, Tan P, Yuan Y, Zhu H (2019) Experimental and analytical investigation of the influence of compressive load on rate-dependent high-damping rubber bearings. Construction and Building Materials 200:26-35.

Wei W, Yuan Y, Igarashi A, Tan P, Lemur H, Zhu HA (2018) Generalized rate-dependent constitutive law for elastomeric bearings. Construction and Building Materials 106:693-699.

Yang YH, Hwang JS, Wang SJ, Shiau CY, Murota N (2016) Seismic response prediction of base-isolated structures with high damping rubber bearings, Journal of the Chinese Institute of Engineers 39(1):12-25.

Zuniga-Cuevas O, Teran-Gilmore A (2013) Parametric study on acceleration-based design of low-rise base isolated systems. Engineering Structures 53:25-37. 
Figures
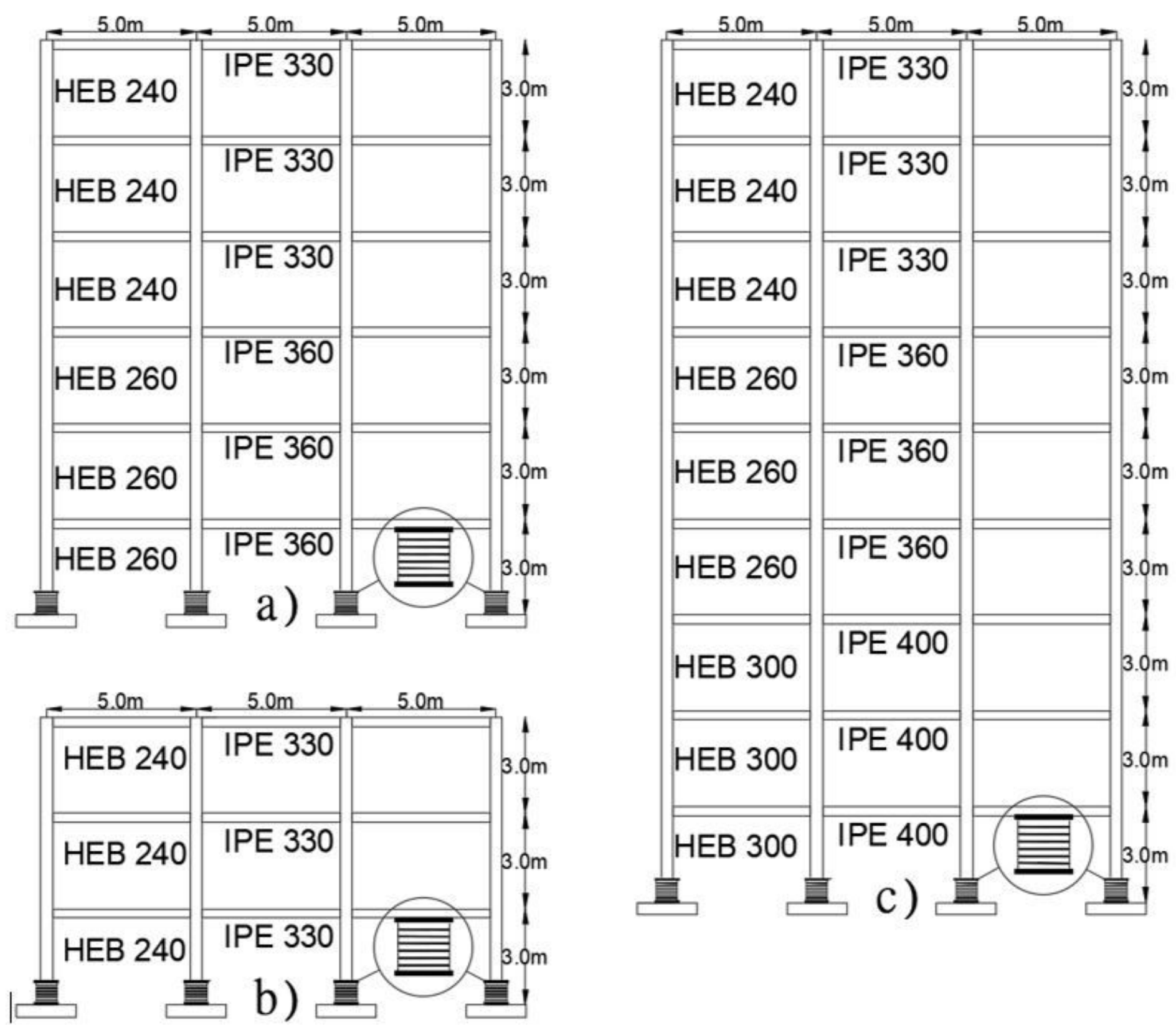

Figure 1

Elevation views of 3,6 , and 9-storey frames with HDRB under investigation. 


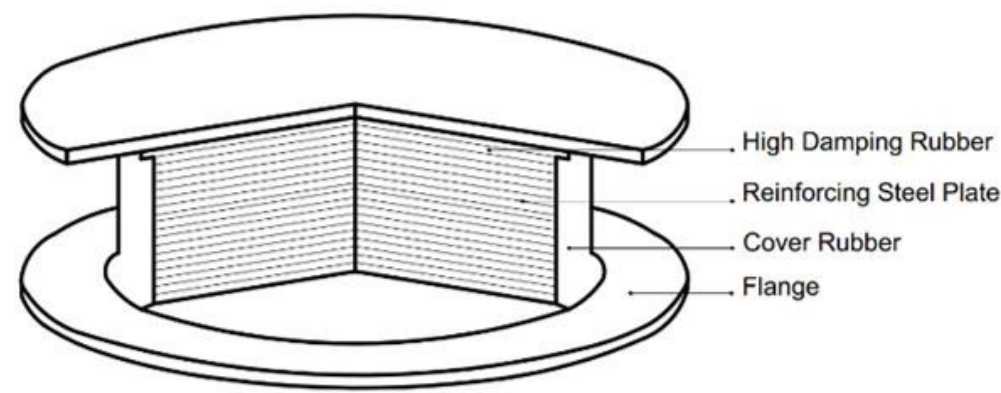

a)

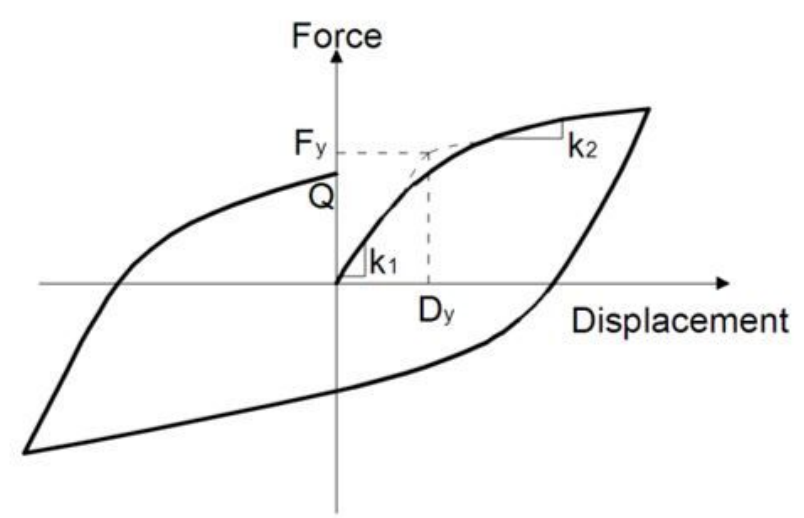

b)

Figure 2

Typical configuration and hysteretic behaviour of HDRB [10]

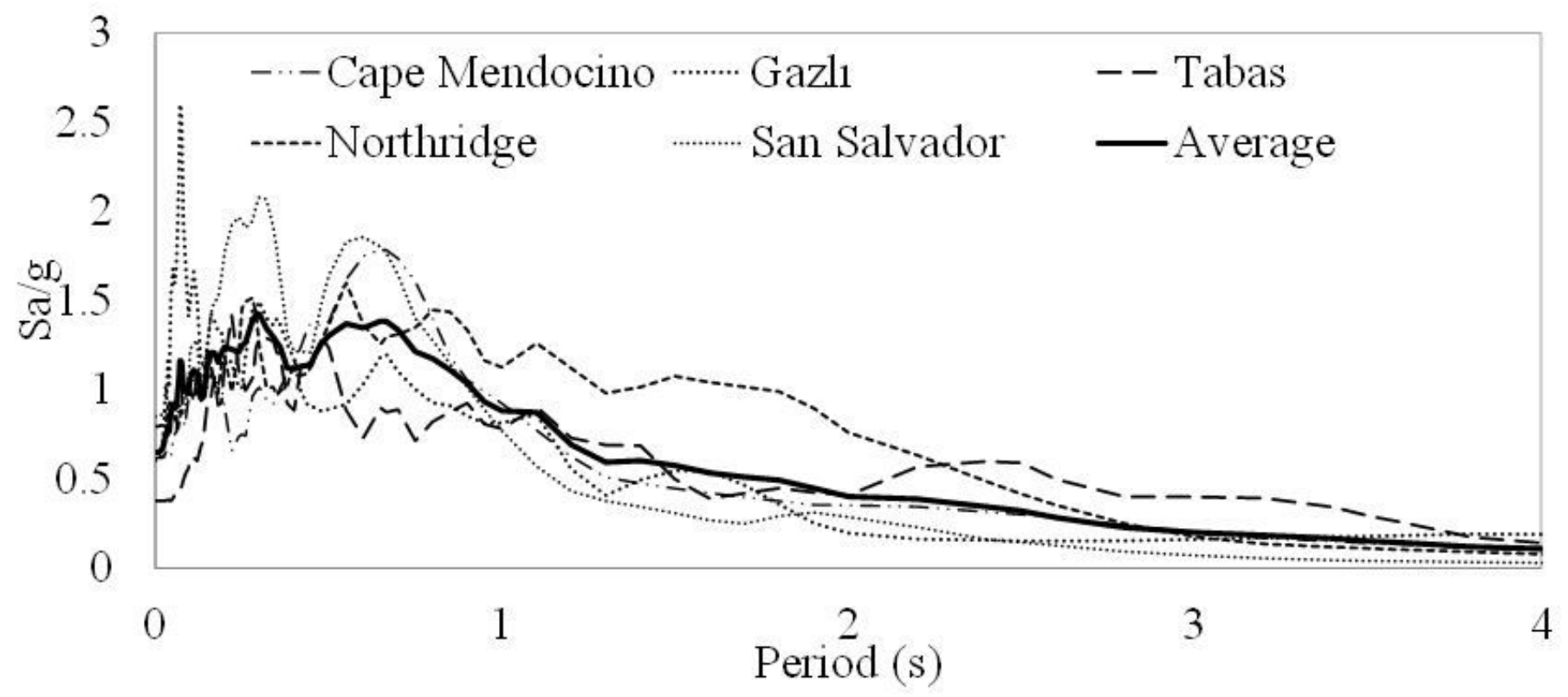

\section{Figure 3}

Elastic acceleration response spectra of the ground motions used.

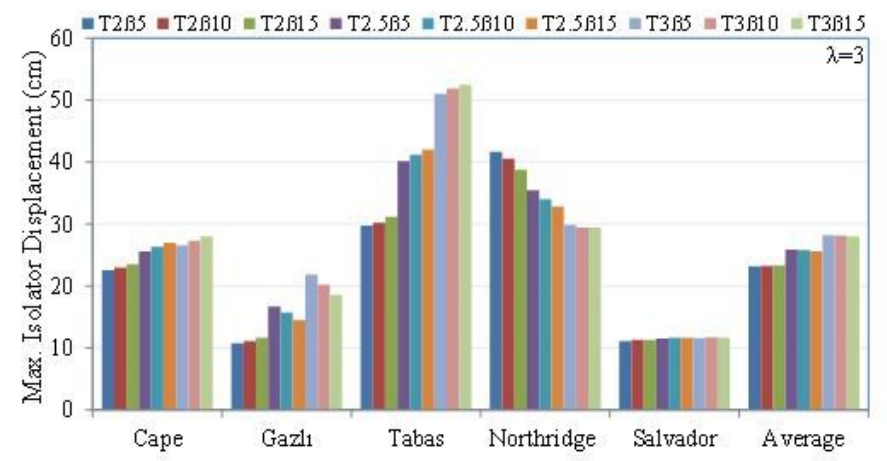

a)

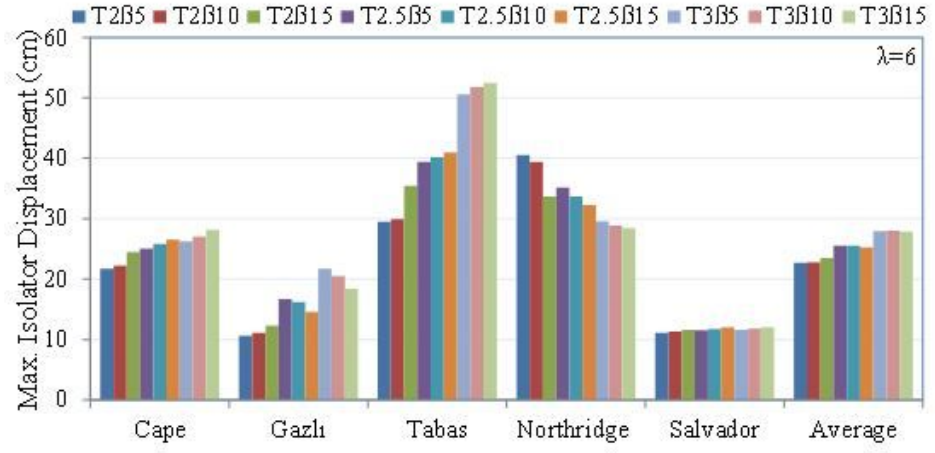

b) 


\section{Figure 4}

Maximum isolator displacement with isolation period, effective damping ratio, and yield strength ratio of 3-storey isolated frames under earthquakes.

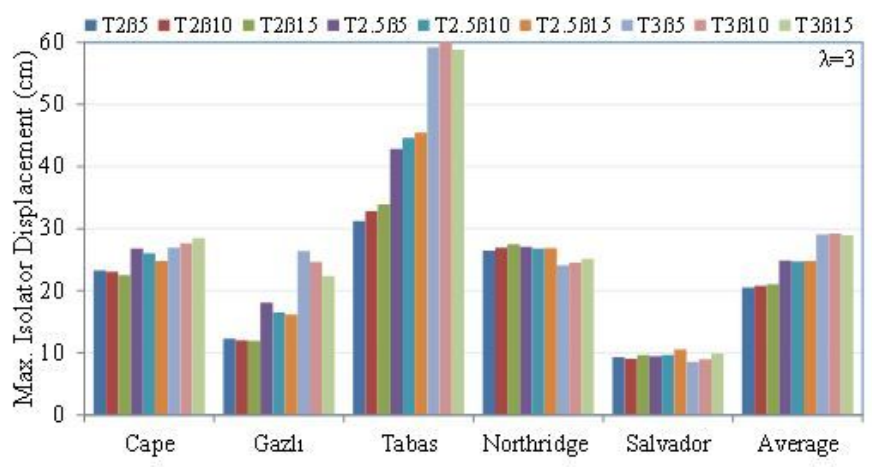

a)

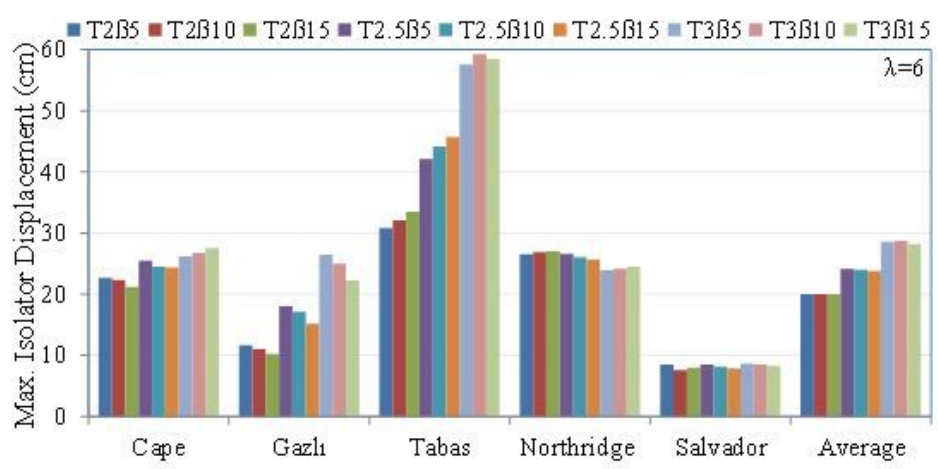

b)

\section{Figure 5}

Maximum isolator displacement with isolation period, effective damping ratio, and yield strength ratio of 6-storey isolated frames under earthquakes.

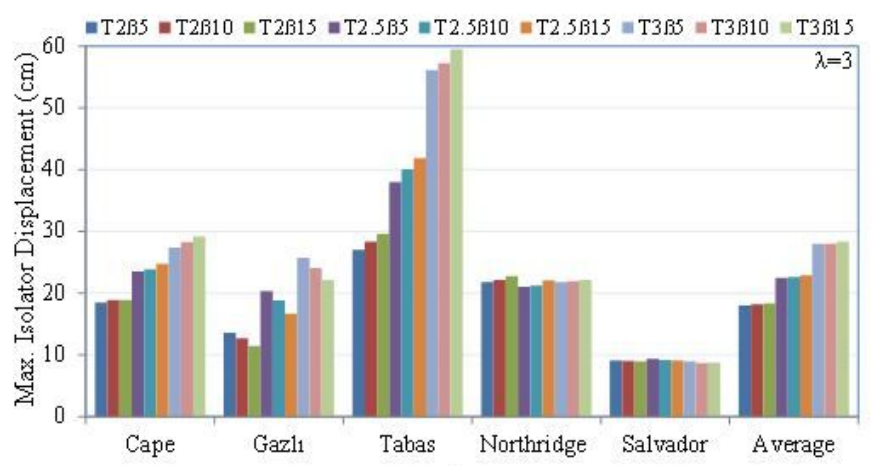

a)

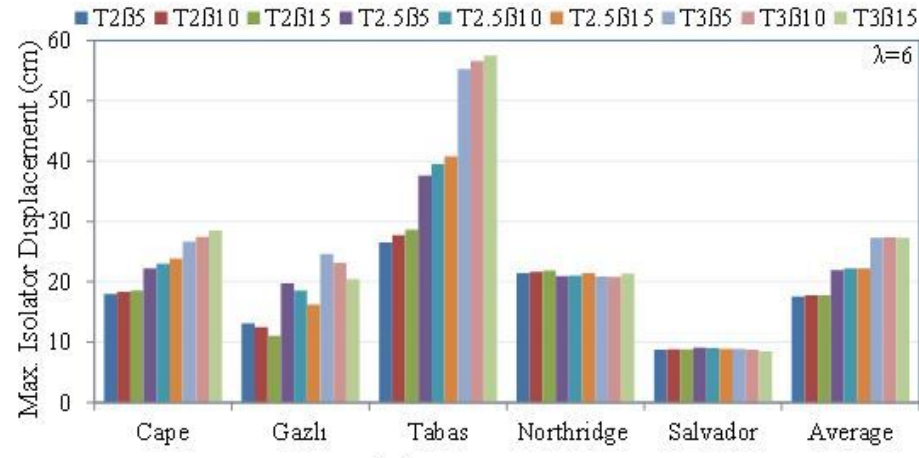

b)

\section{Figure 6}

Maximum isolator displacement with isolation period, effective damping ratio, and yield strength ratio of 9-storey isolated frames under earthquakes.

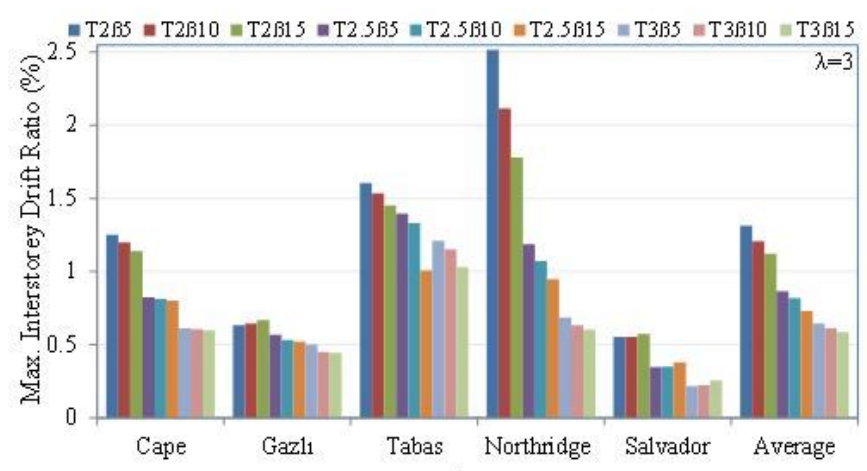

a)

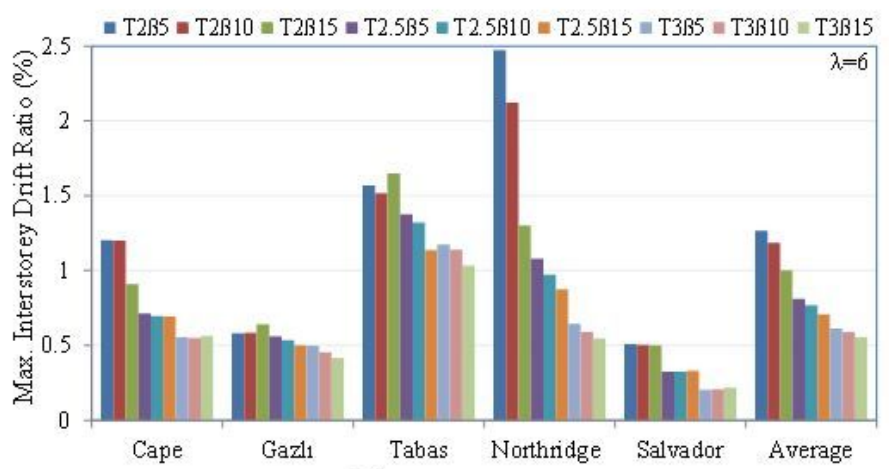

b) 


\section{Figure 7}

Maximum interstorey drift ratio with isolation period, effective damping ratio, and yield strength ratio of 3storey isolated frames under earthquakes.

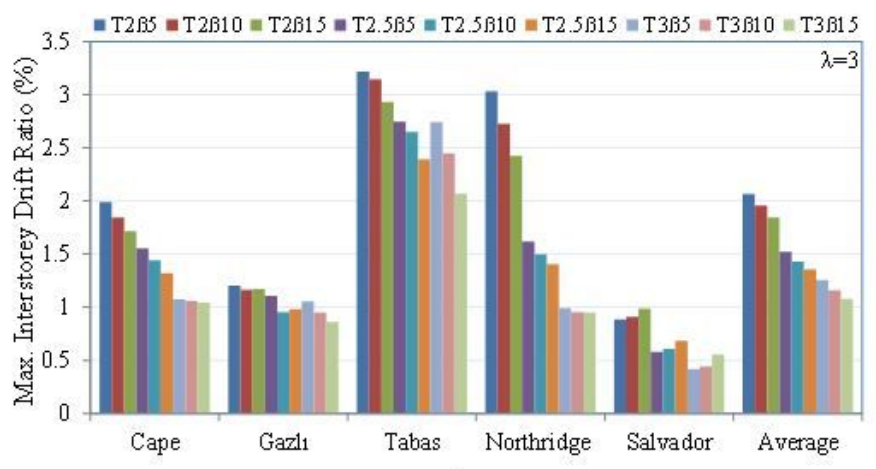

a)

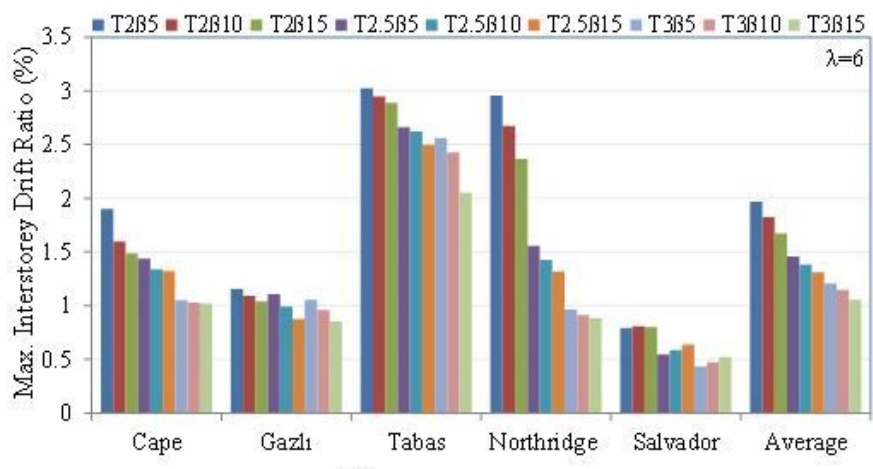

b)

\section{Figure 8}

Maximum interstorey drift ratio with isolation period, effective damping ratio, and yield strength ratio of 6storey isolated frames under earthquakes.

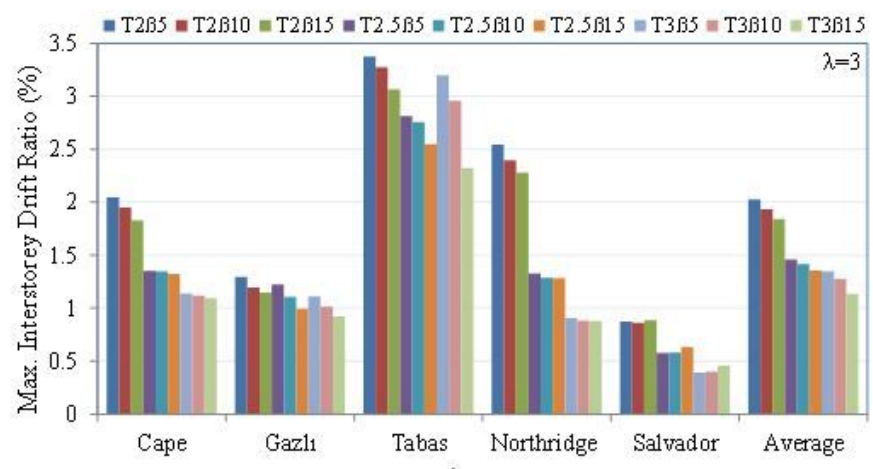

a)

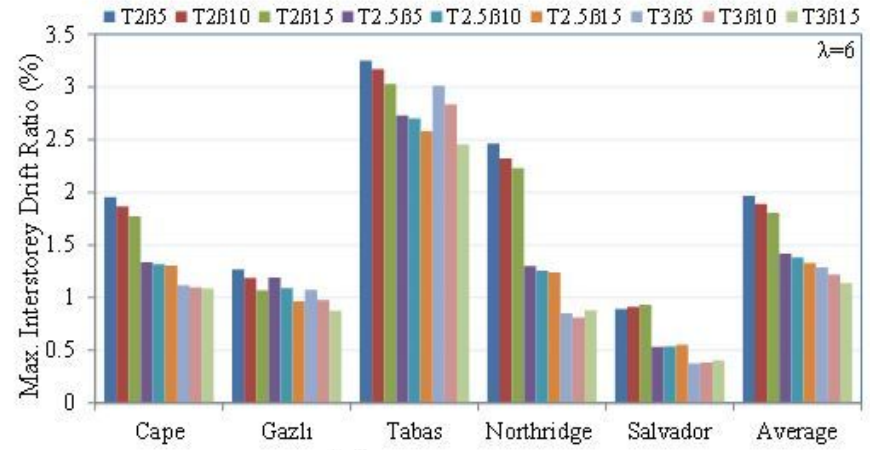

b)

\section{Figure 9}

Maximum interstorey drift ratio with isolation period, effective damping ratio, and yield strength ratio of 9storey isolated frames under earthquakes.

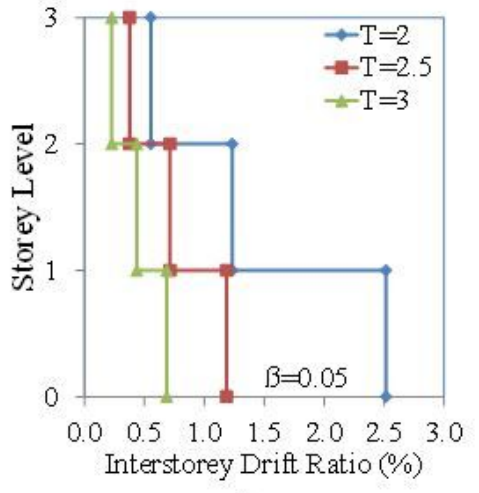

a)

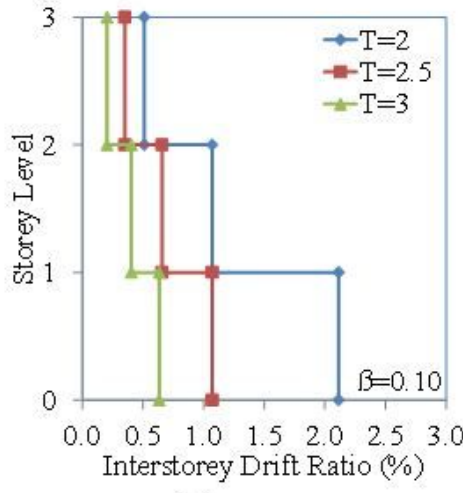

b)

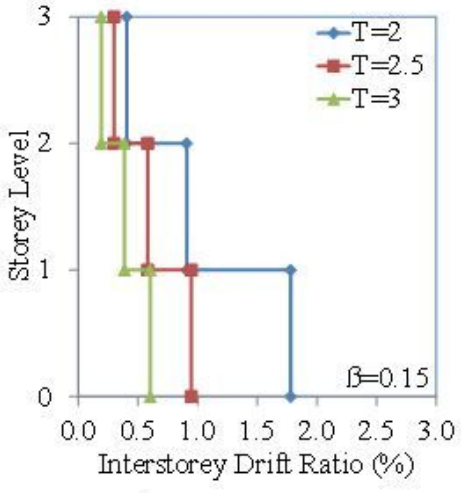

c) 
Figure 10

Interstorey drifts against storey height of 3-storey isolated frames under Northridge earthquake for $\lambda=3$

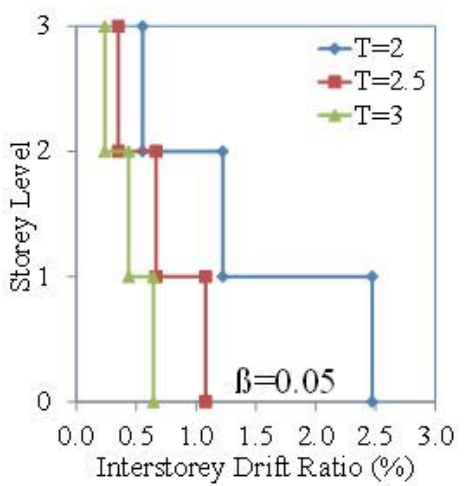

a)

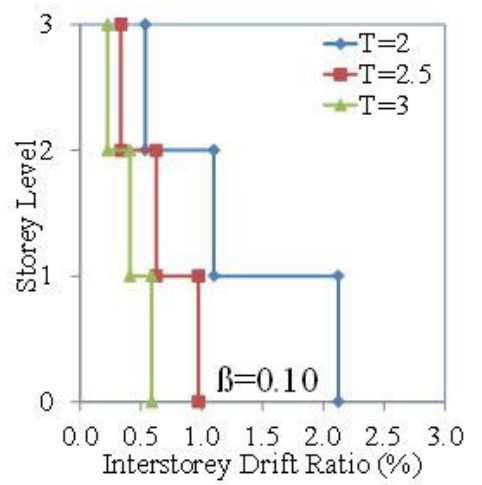

b)

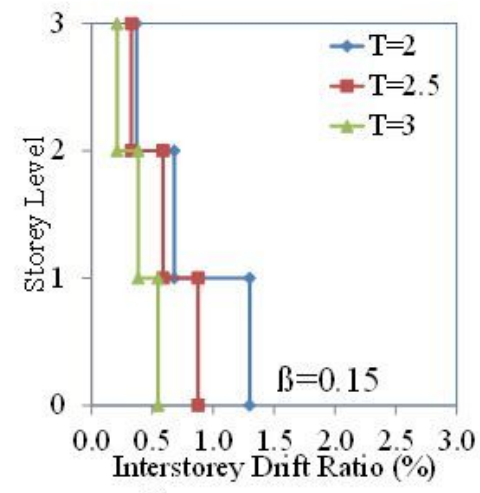

c)

\section{Figure 11}

Interstorey drifts against storey height of 3-storey isolated frames under Northridge earthquake for $\lambda=6$

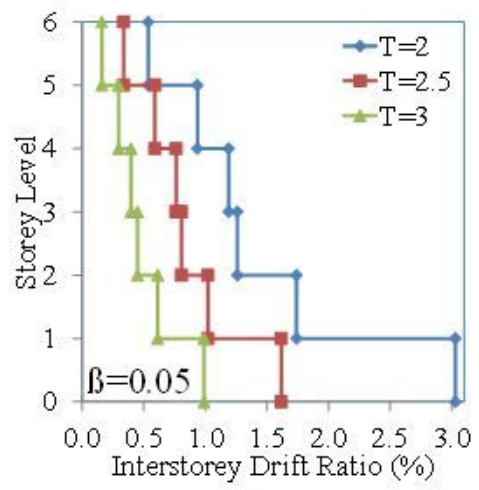

a)

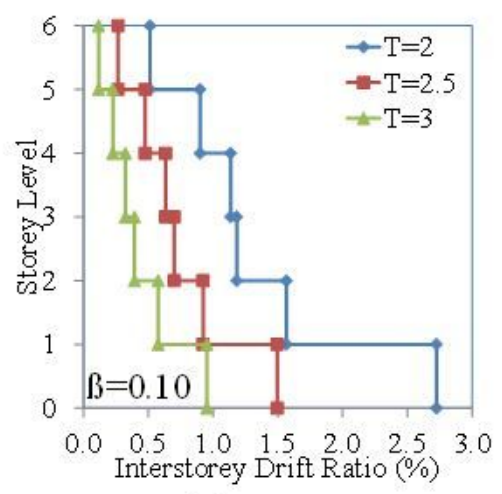

b)

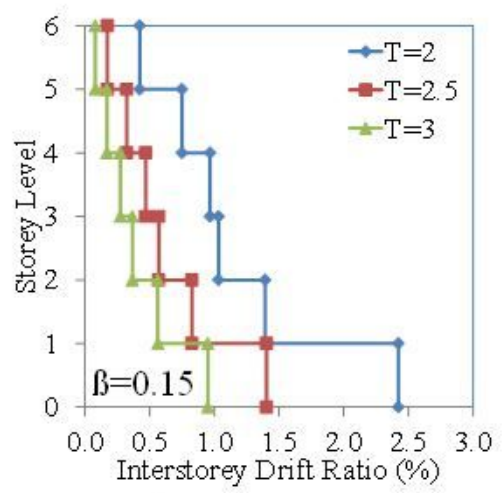

c)

Figure 12

Interstorey drifts against storey height of 6-storey isolated frames under Northridge earthquake for $\lambda=3$

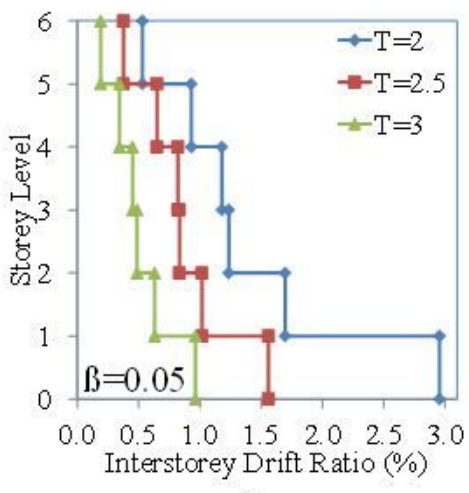

a)

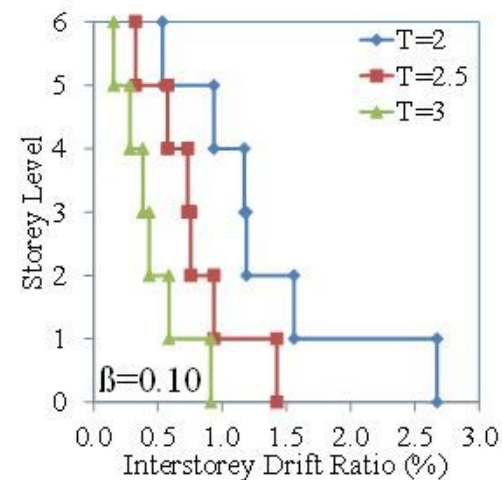

b)

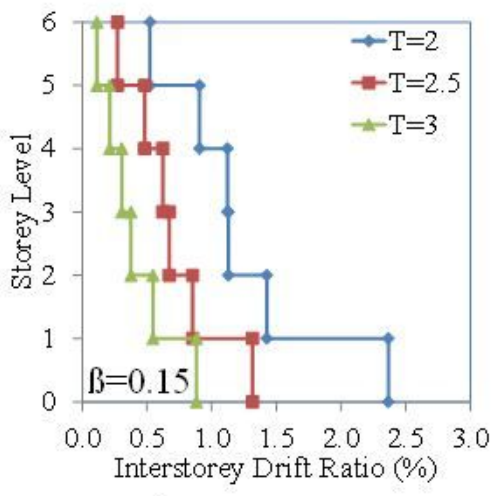

c) 
Interstorey drifts against storey height of 6-storey isolated frames under Northridge earthquake for $\lambda=6$

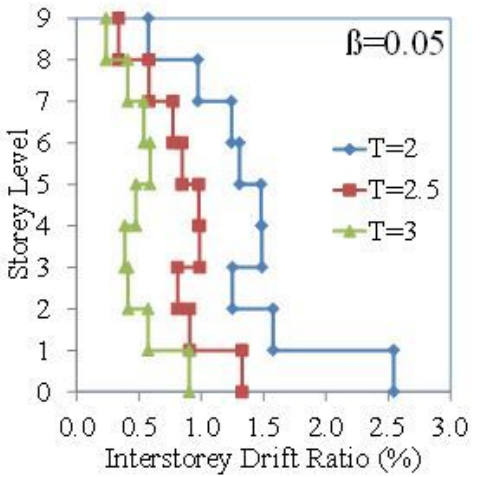

a)

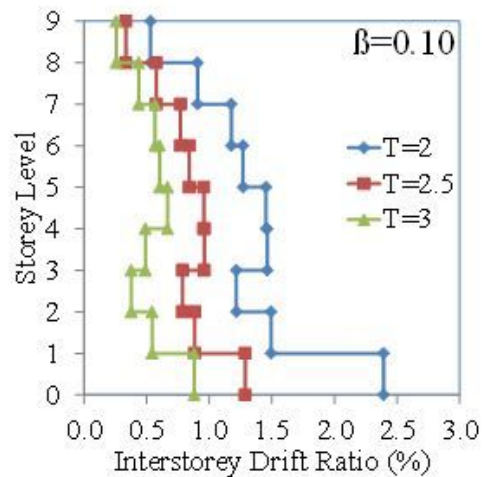

b)

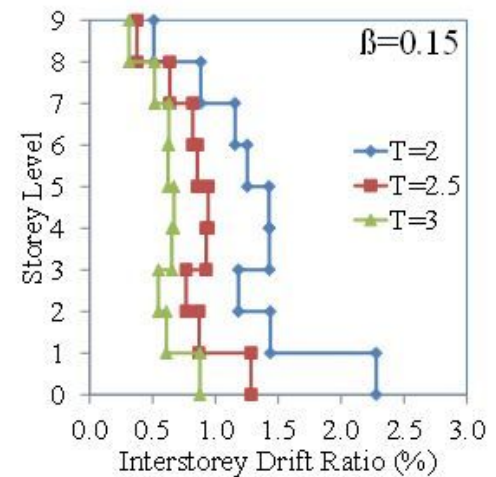

c)

\section{Figure 14}

Interstorey drifts against storey height of 9-storey isolated frames under Northridge earthquake for $\lambda=3$

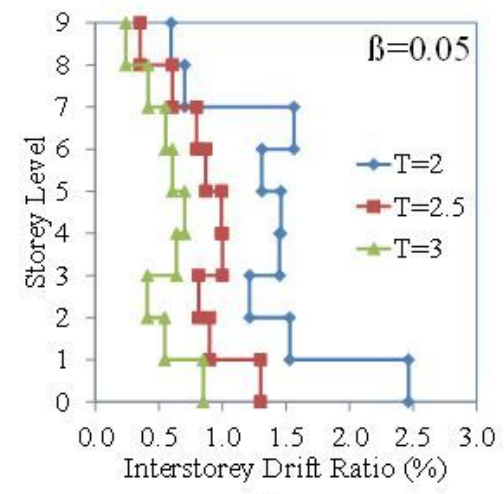

a)

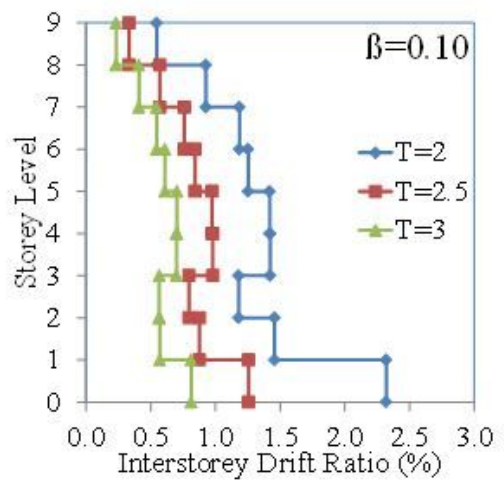

b)

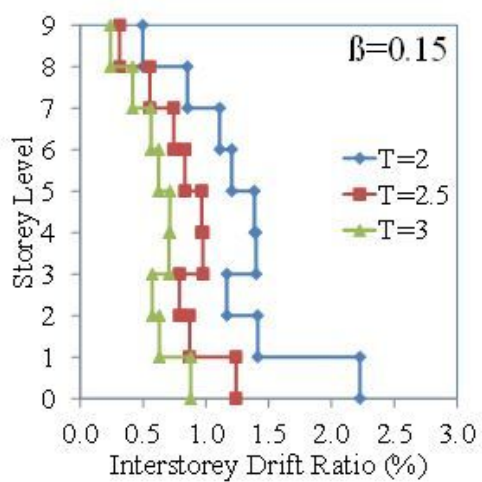

c)

\section{Figure 15}

Interstorey drifts against storey height of 9-storey isolated frames under Northridge earthquake for $\lambda=6$

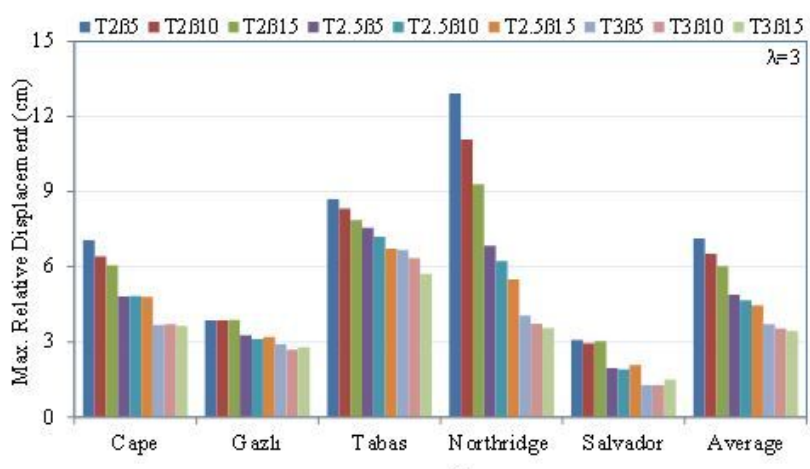

a)

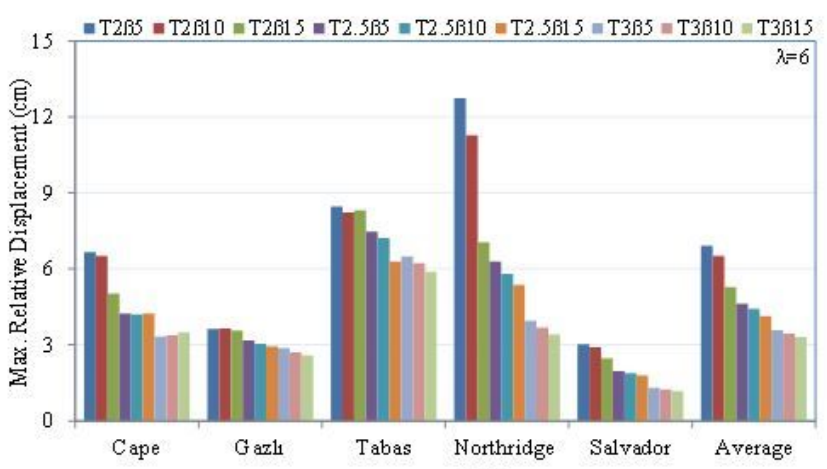

b)

Figure 16

Maximum relative displacement of 3-storey isolated frames. 


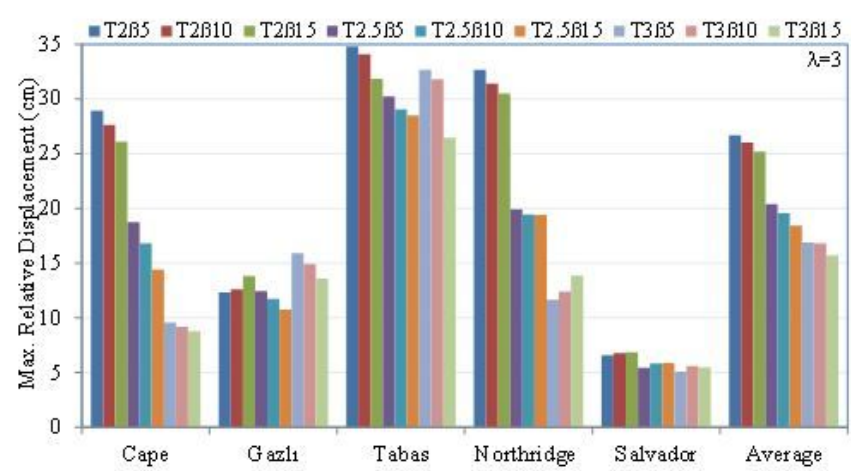

a)

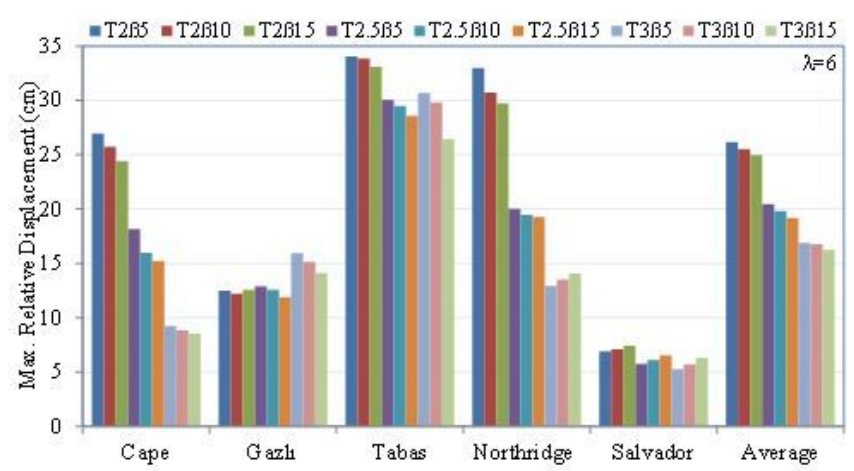

b)

\section{Figure 18}

Maximum relative displacement of 9-storey isolated frames.

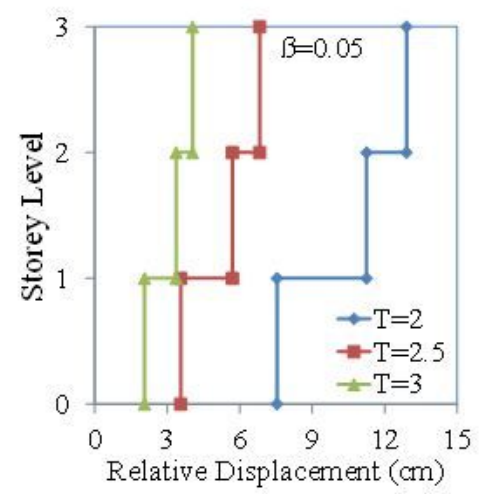

a)

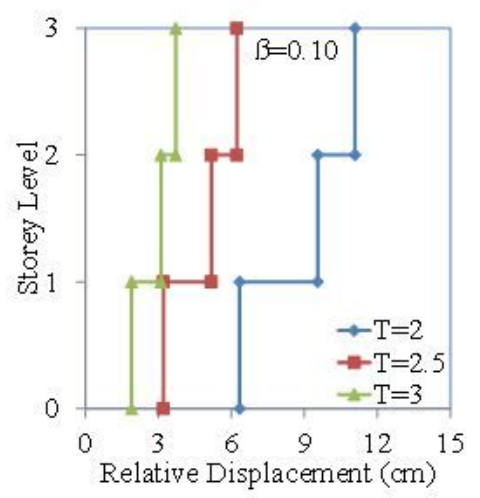

b)

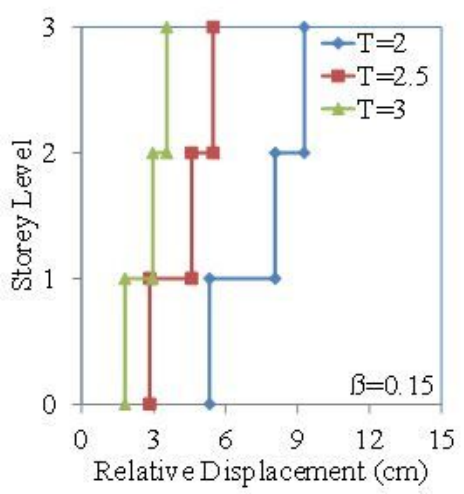

c)

\section{Figure 19}

Relative displacement against storey height of 3-storey isolated frames under Northridge earthquake for $\lambda=3$

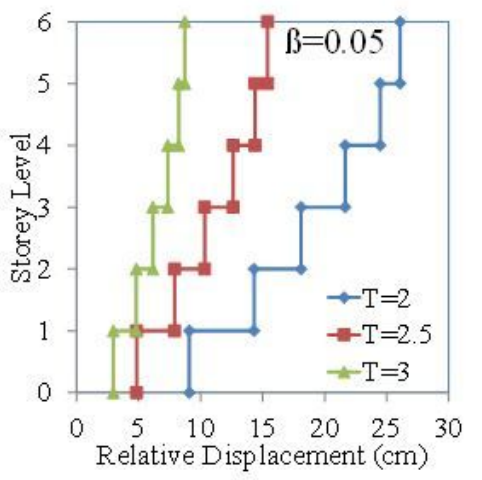

a)

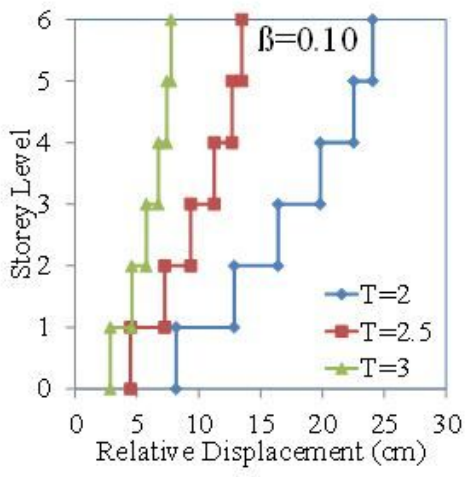

b)

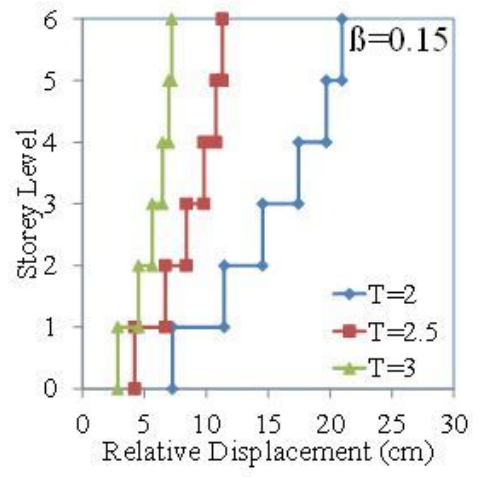

c)

\section{Figure 21}

Relative displacement against storey height of 6-storey isolated frames under Northridge earthquake for $\lambda=3$ 


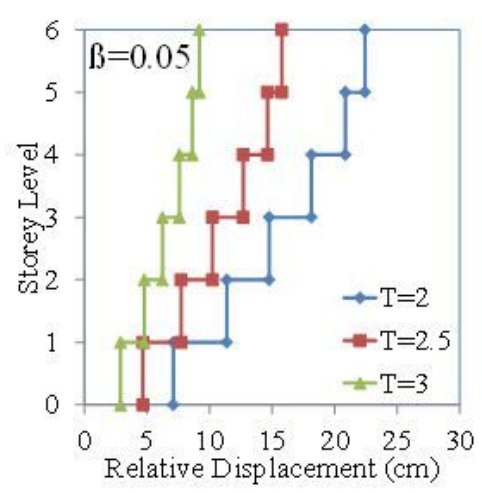

a)

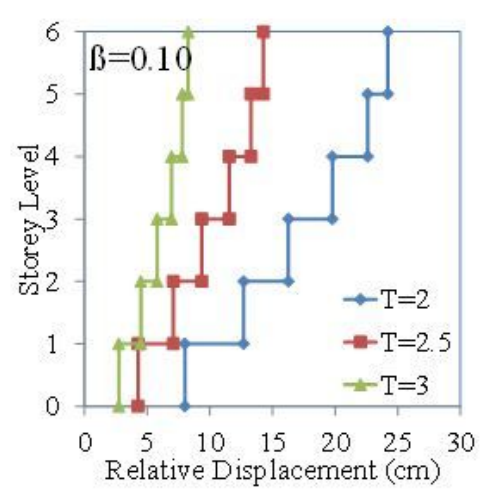

b)

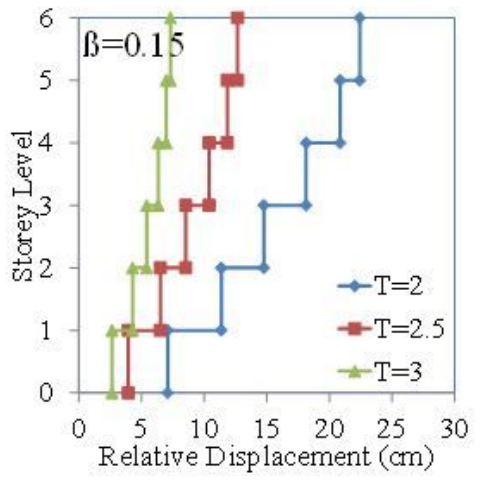

c)

Figure 22

Relative displacement against storey height of 6-storey isolated frames under Northridge earthquake for $\lambda=6$

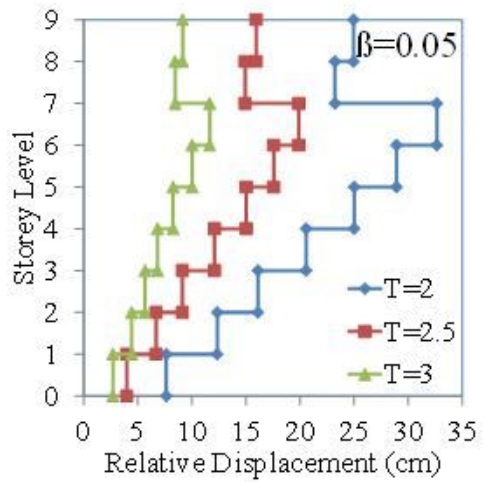

a)

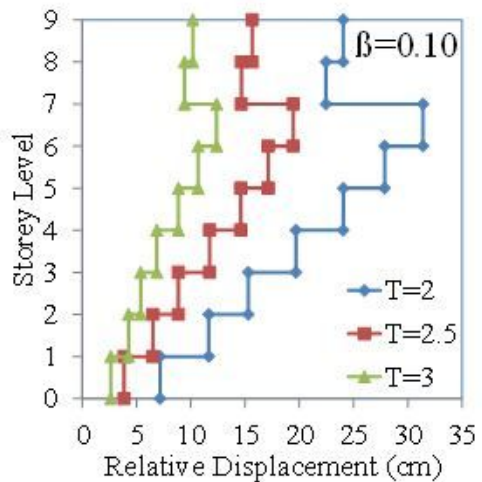

b)

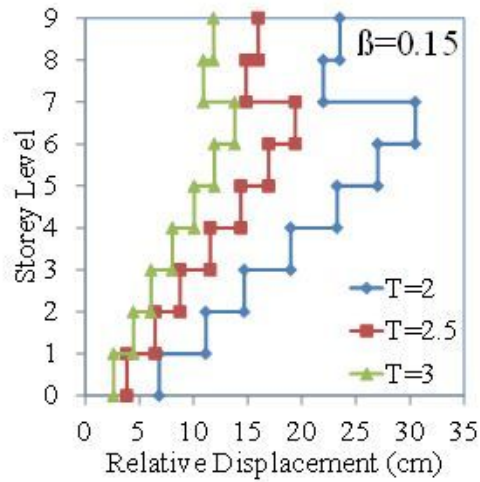

c)

Figure 23

Relative displacement against storey height of 9-storey isolated frames under Northridge earthquake for $\lambda=3$

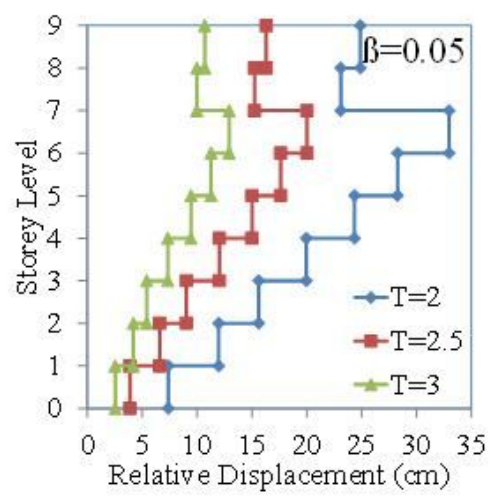

a)

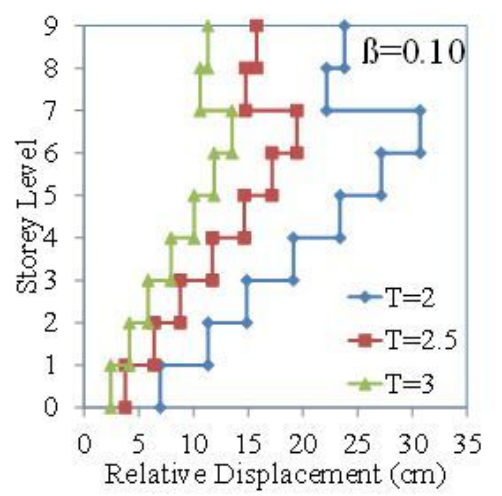

b)

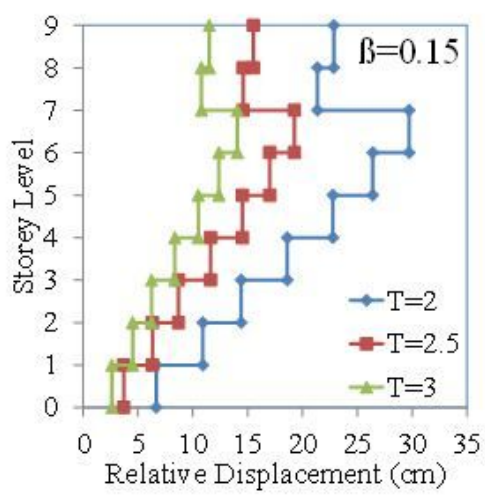

c)

\section{Figure 24}


Relative displacement against storey height of 9-storey isolated frames under Northridge earthquake for $\lambda=6$

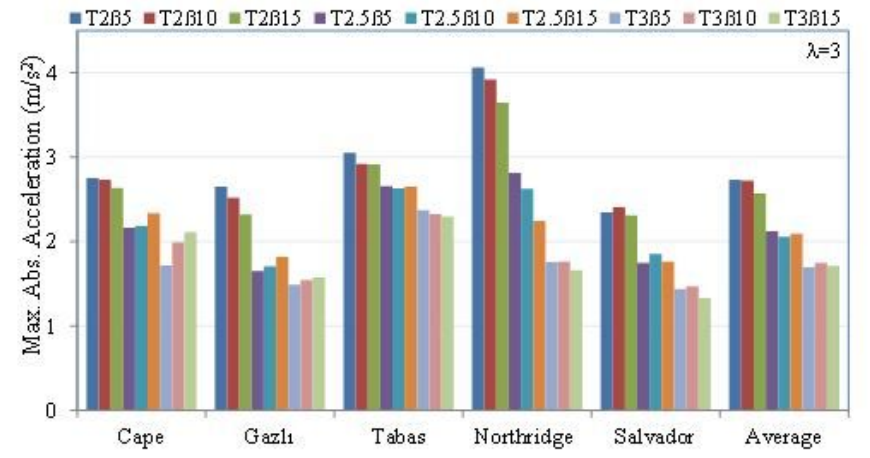

a)

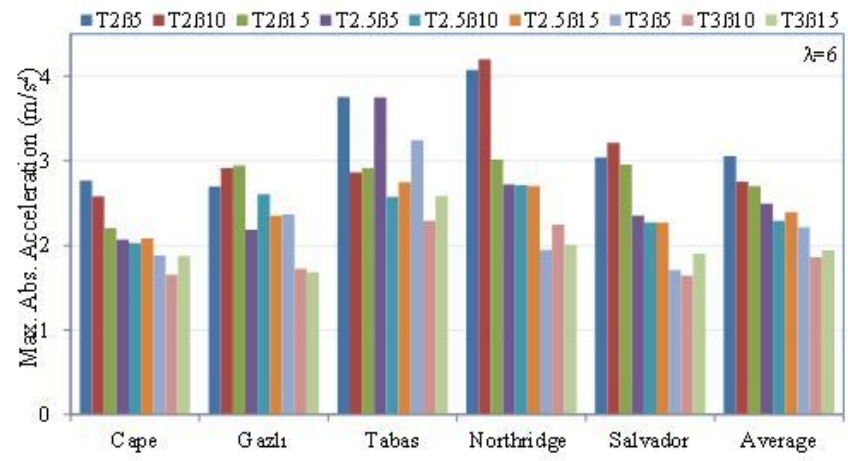

b)

Figure 25

Maximum absolute acceleration of 3-storey isolated frames.

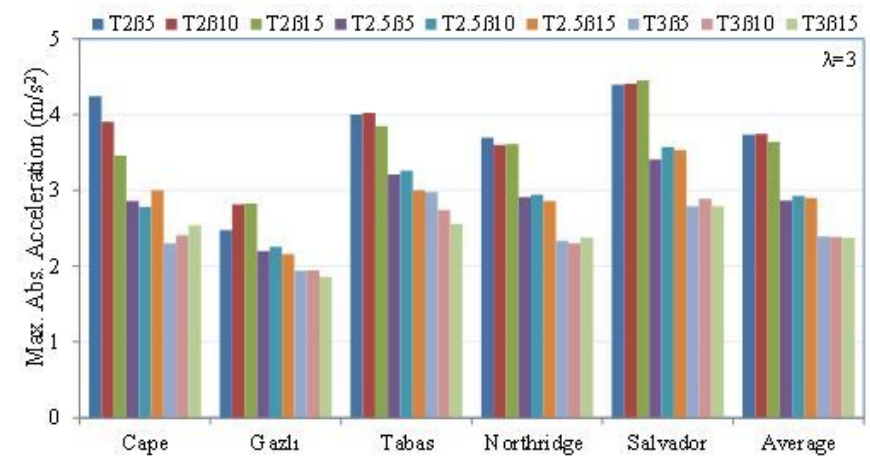

a)

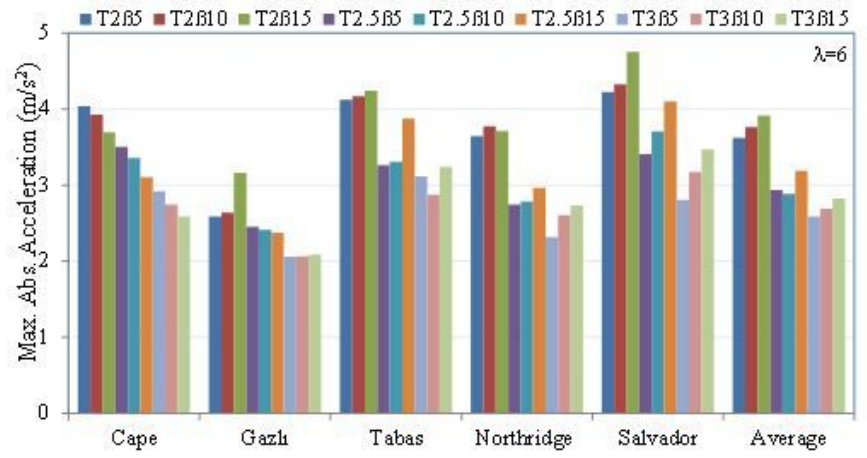

b)

\section{Figure 26}

Maximum absolute acceleration of 6-storey isolated frames.

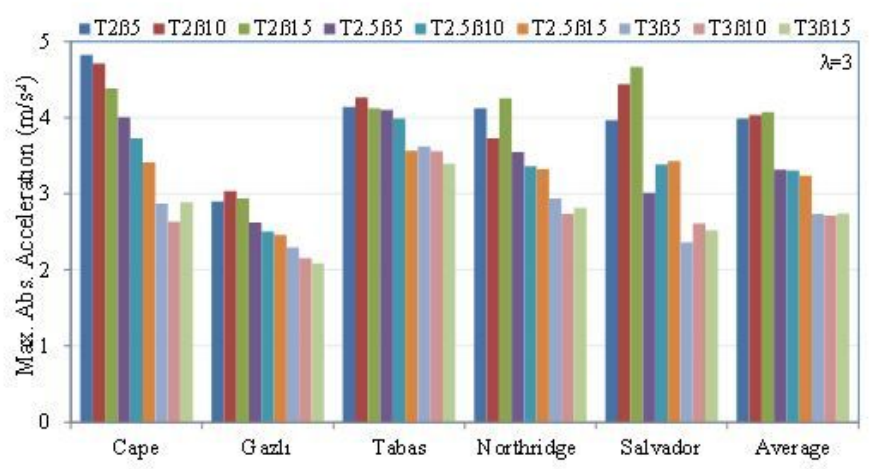

a)

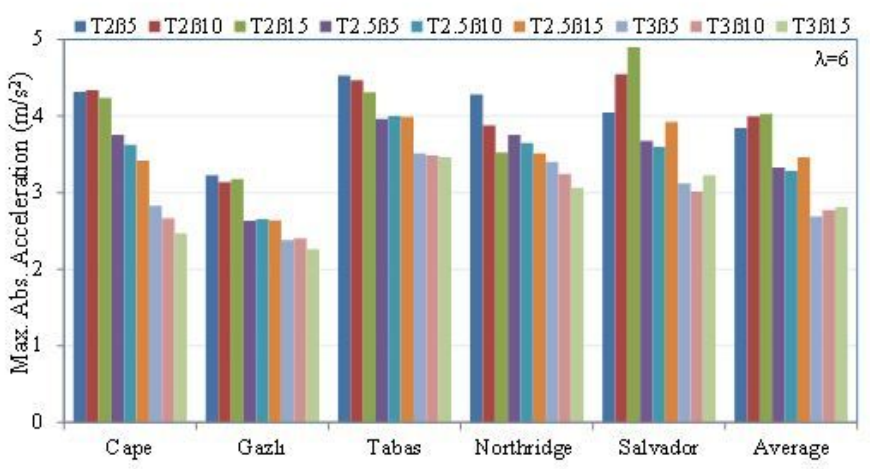

b)

\section{Figure 27}

Maximum absolute acceleration of 9-storey isolated frames. 


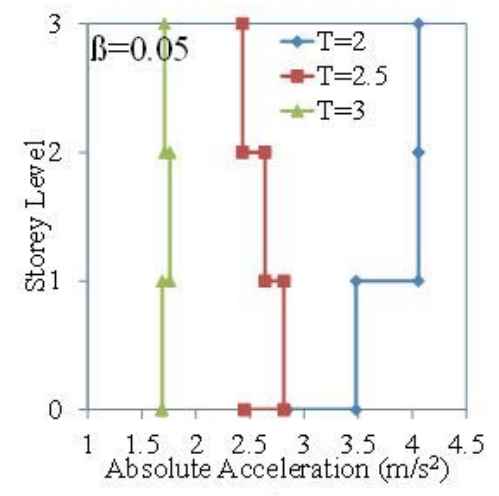

a)

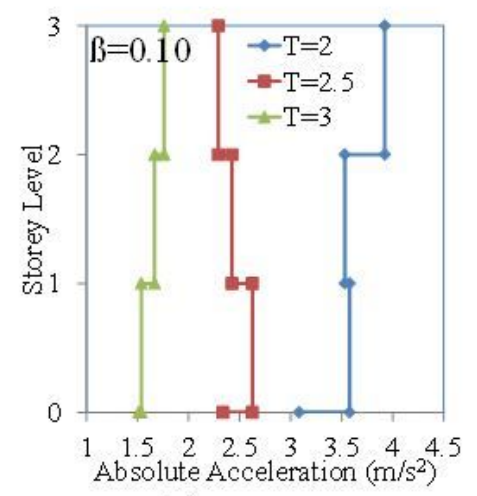

b)

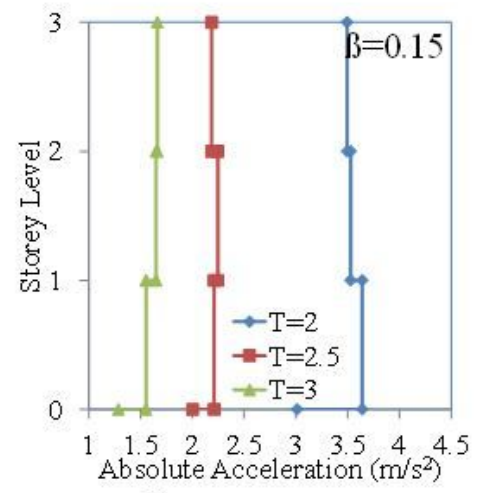

c)

Figure 28

Absolute acceleration against storey height of 3-storey isolated frames under Northridge earthquake for $\lambda=3$

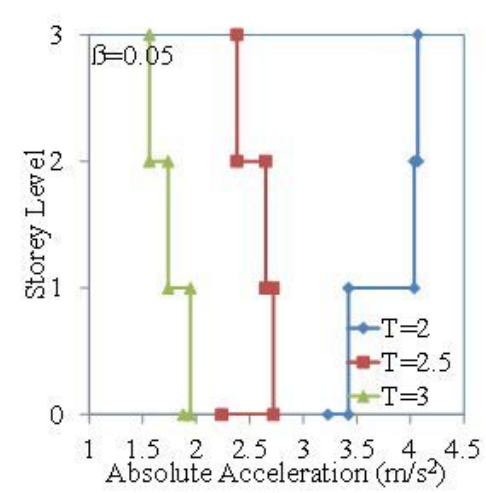

a)

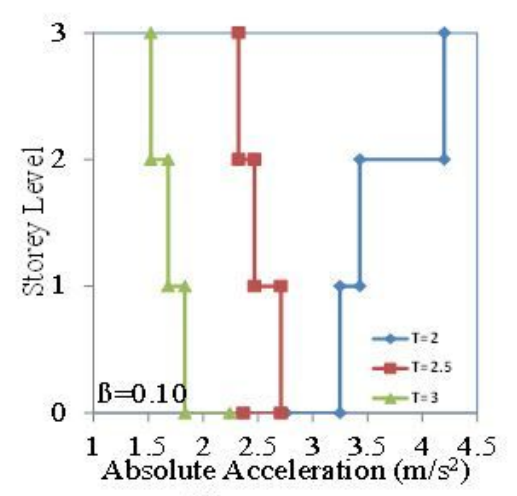

b)

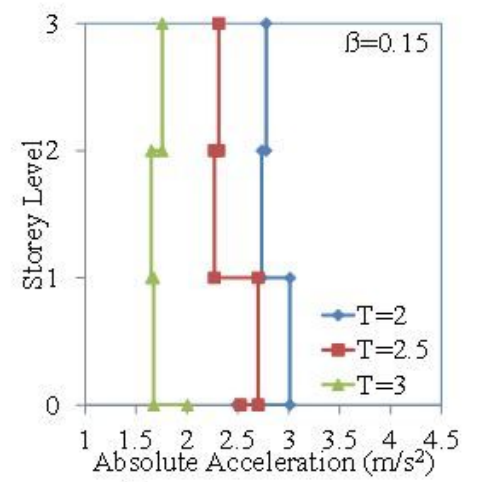

c)

Figure 29

Absolute acceleration against storey height of 3-storey isolated frames under Northridge earthquake for $\lambda=6$

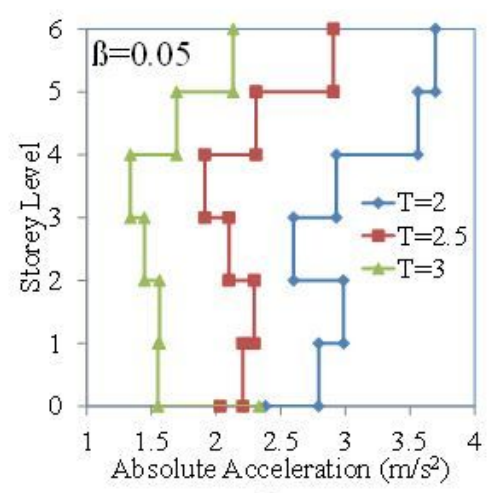

a)

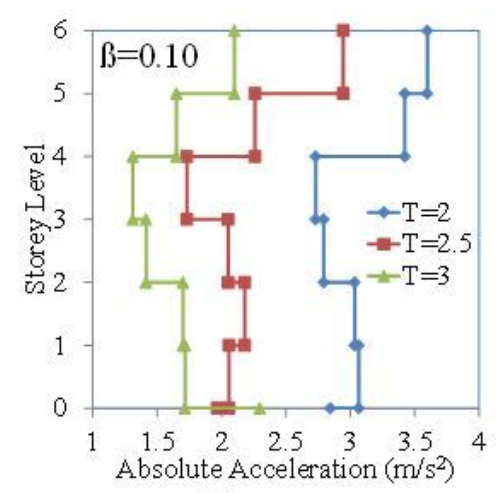

b)

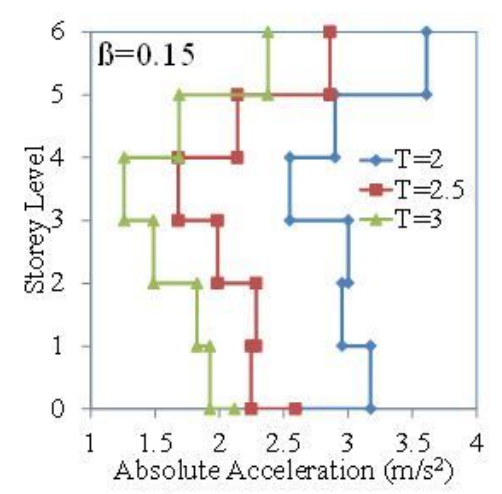

c)

\section{Figure 30}


Absolute acceleration against storey height of 6-storey isolated frames under Northridge earthquake for $\lambda=3$

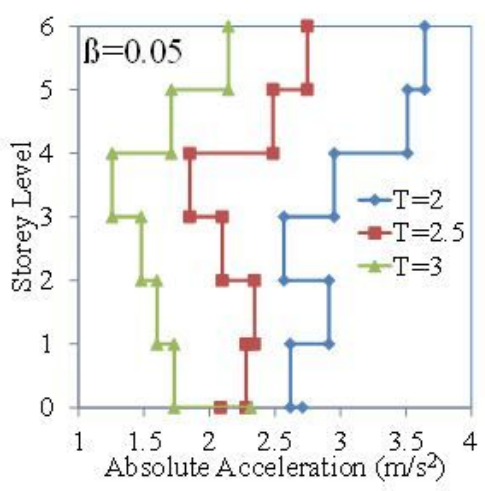

a)

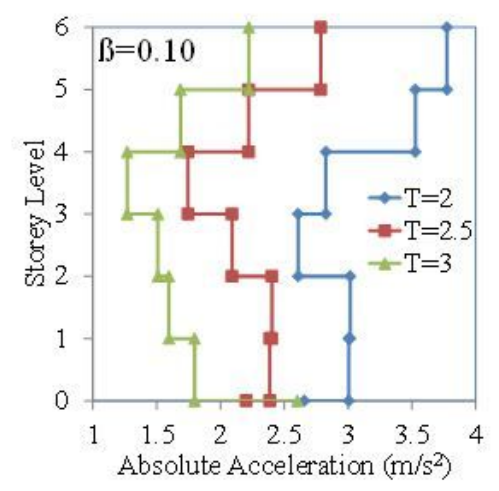

b)

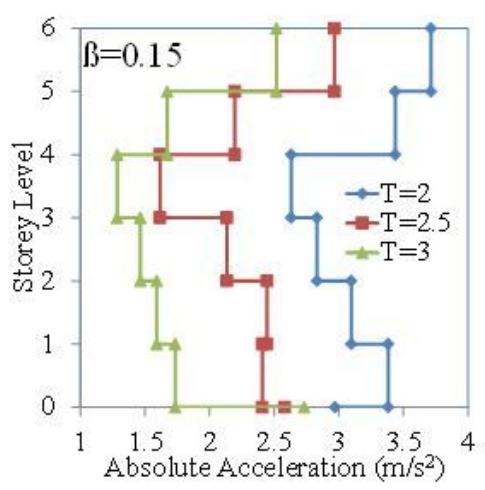

c)

\section{Figure 31}

Absolute acceleration against storey height of 6-storey isolated frames under Northridge earthquake for $\lambda=6$

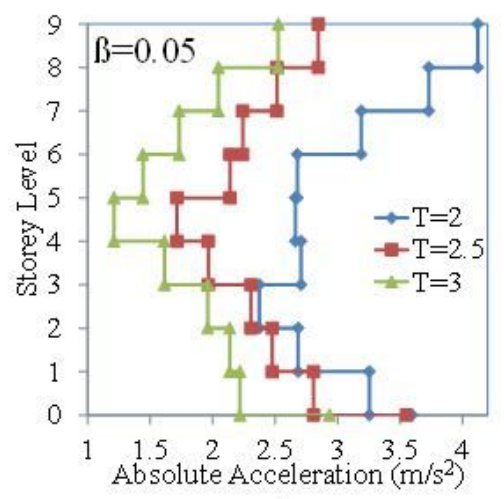

a)

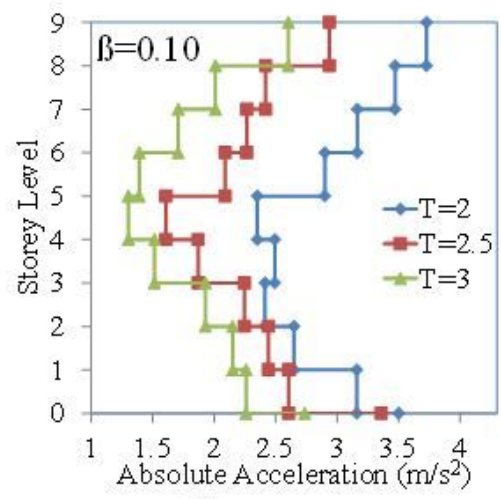

b)

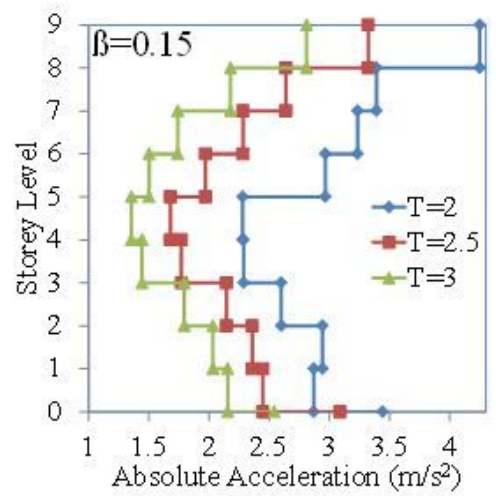

c)

\section{Figure 32}

Absolute acceleration against storey height of 9-storey isolated frames under Northridge earthquake for $\lambda=3$

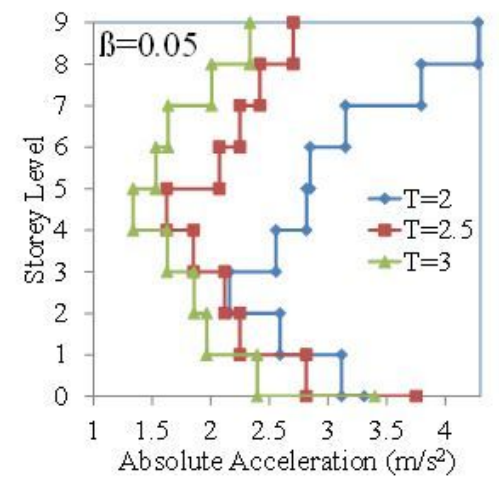

a)

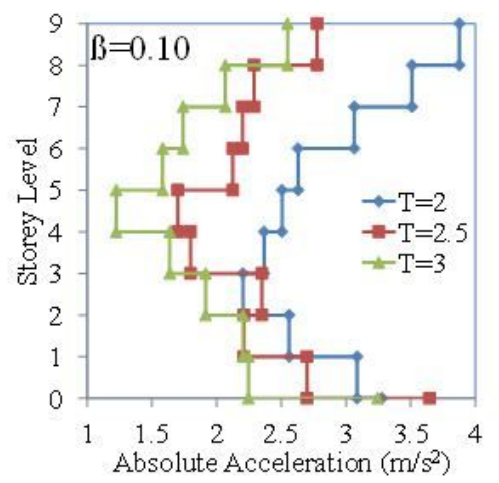

b)

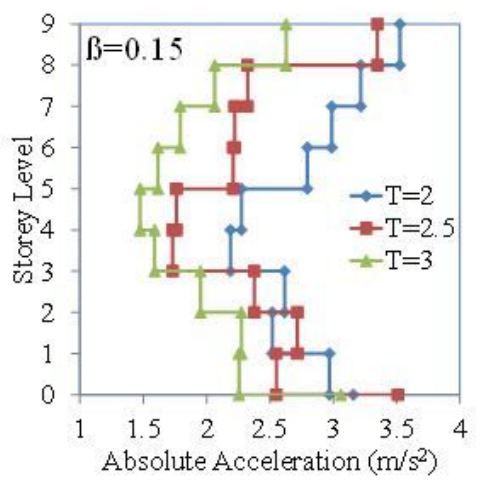

c) 
Figure 33

Absolute acceleration against storey height of 9-storey isolated frames under Northridge earthquake for $\lambda=6$

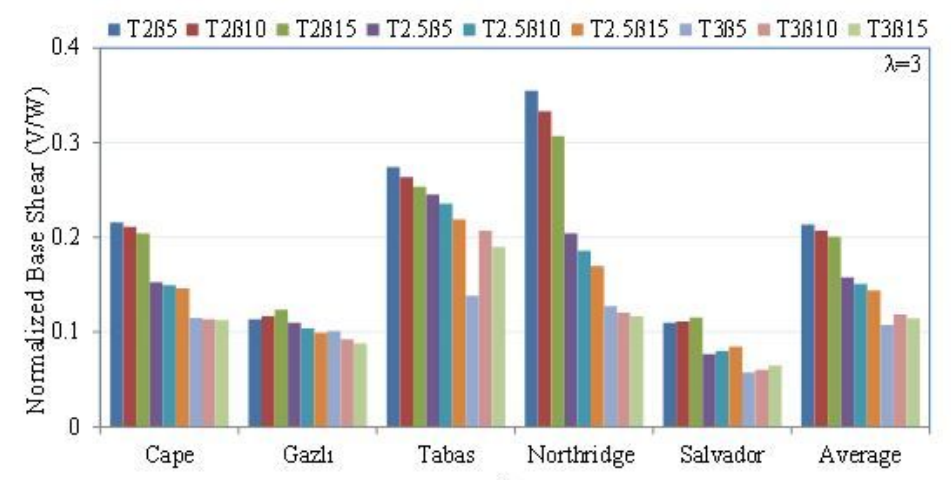

a)

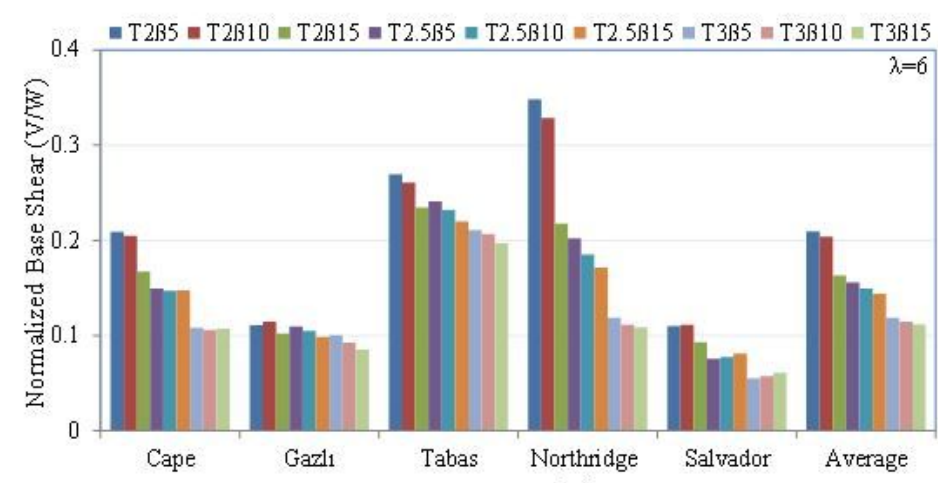

b)

Figure 34

Maximum base shear of 3-storey isolated frames.

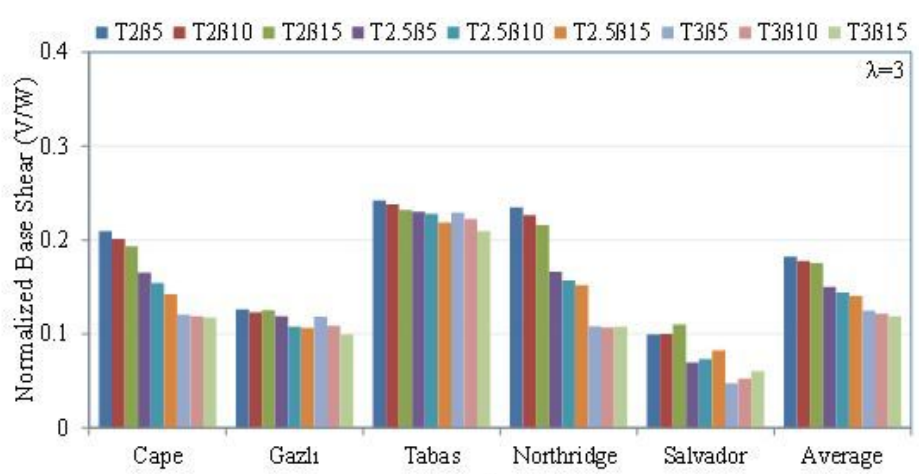

a)

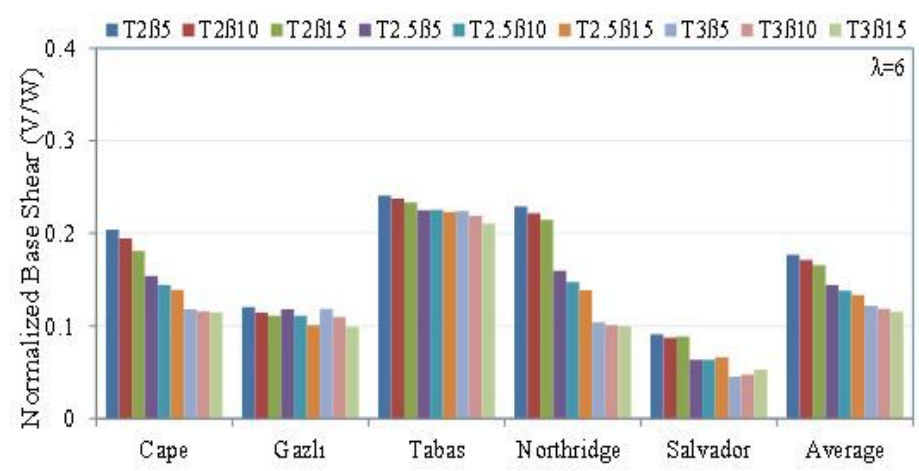

b)

\section{Figure 35}

Maximum base shear of 6-storey isolated frames.

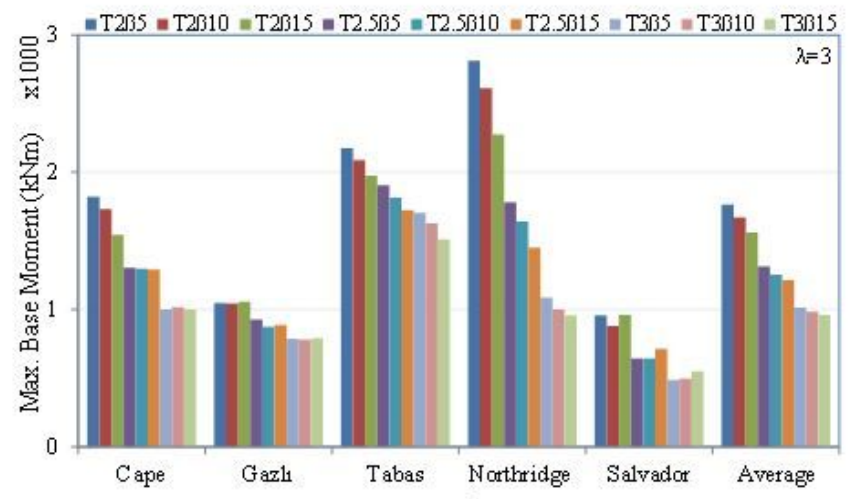

a)

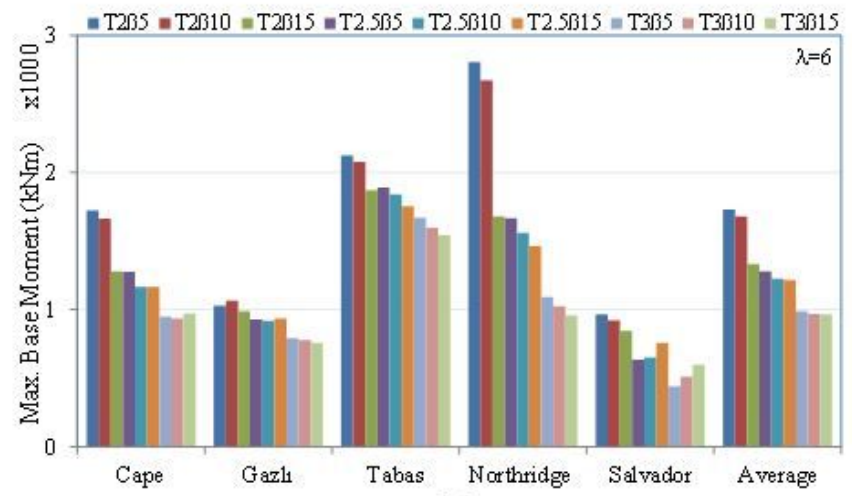

b) 
Maximum base moment of 3-storey isolated frames.

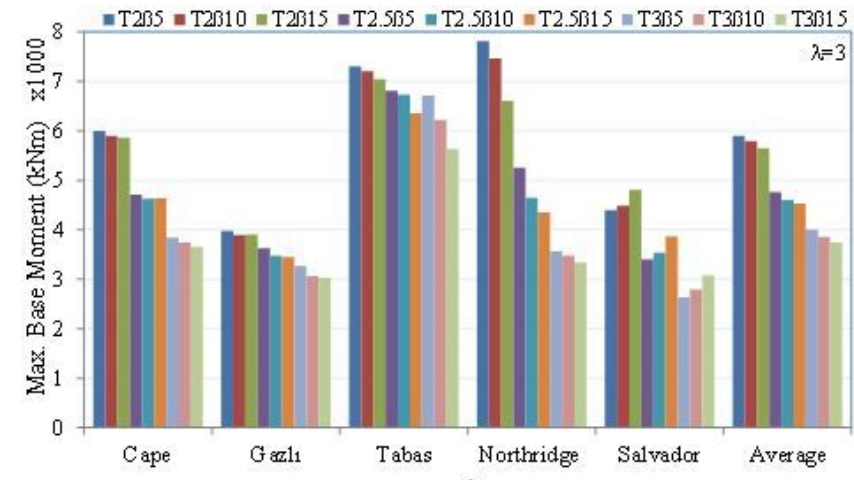

a)

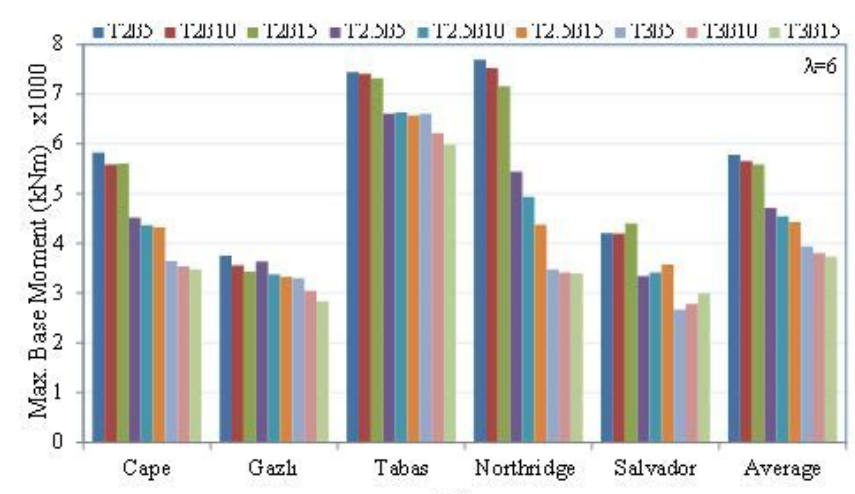

b)

\section{Figure 38}

Maximum base moment of 6-storey isolated frames.

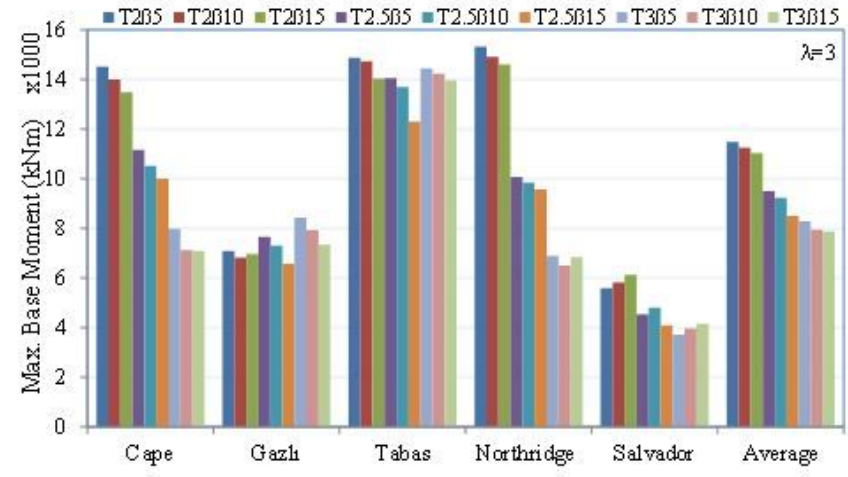

a)

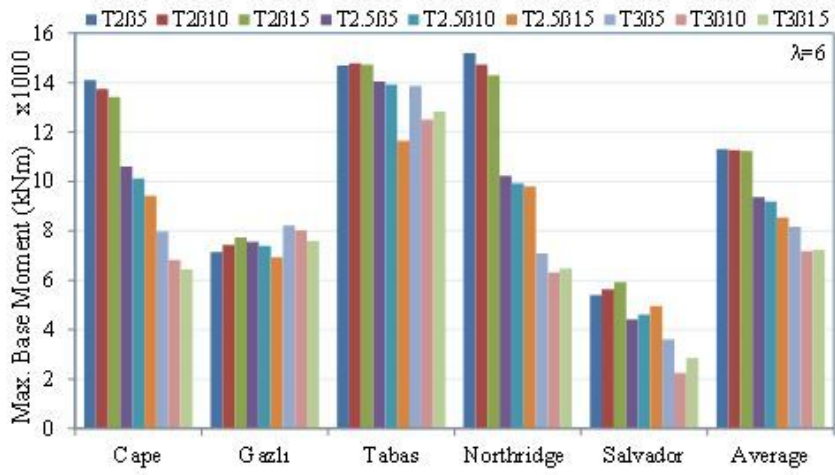

b)

Figure 39

Maximum base moment of 9-storey isolated frames.

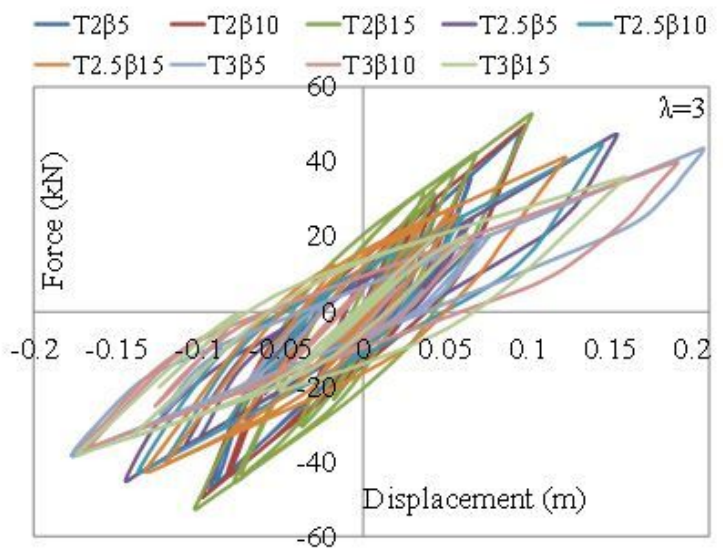

a)

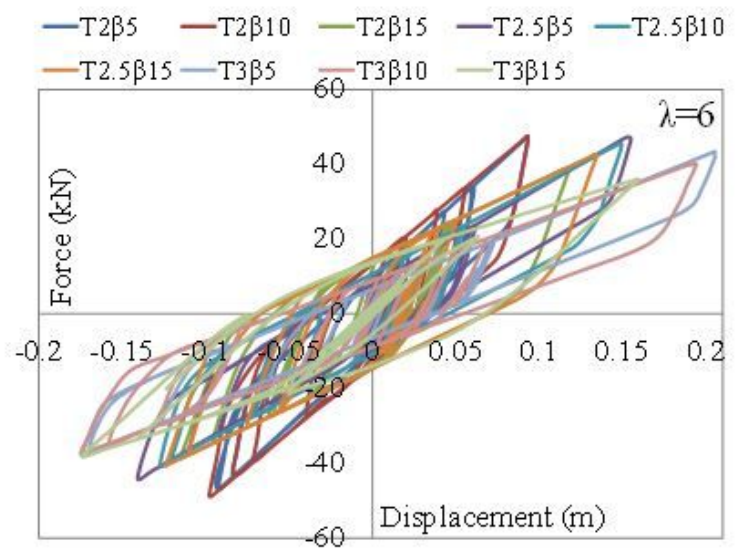

b)

\section{Figure 40}

Bi-linear force-deformation relation of 3-storey frame with HDRB under Gazlı earthquake. 


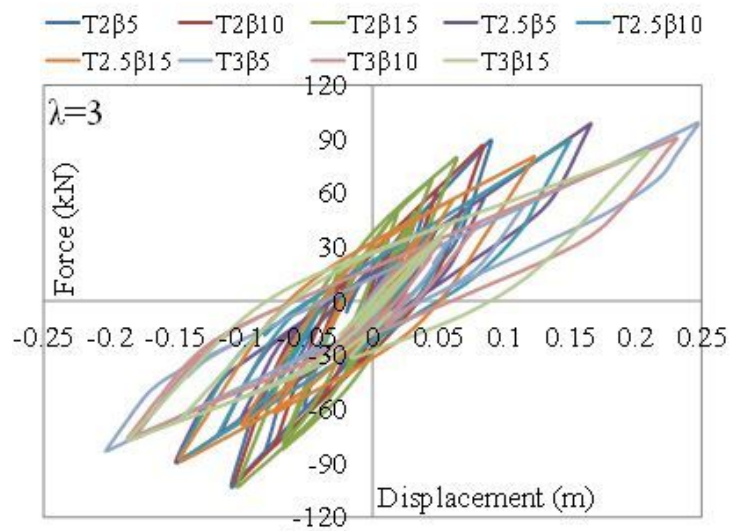

a)

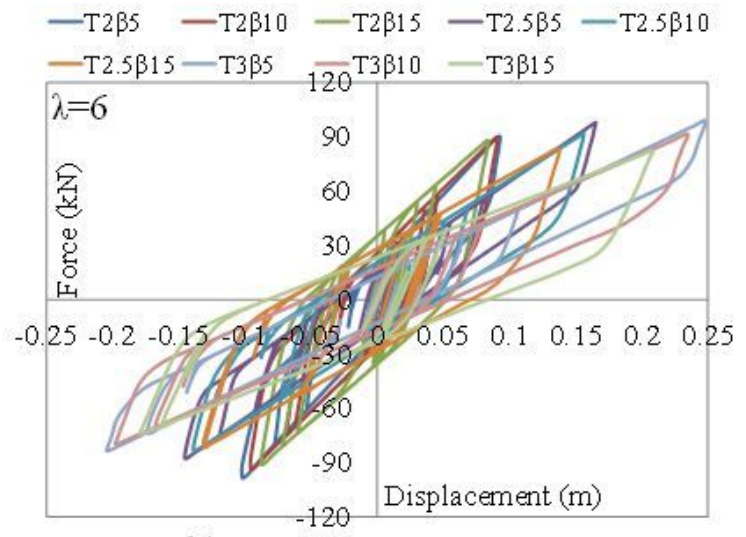

b)

\section{Figure 41}

Bi-linear force-deformation relation of 6-storey frame with HDRB under Gazlı earthquake.

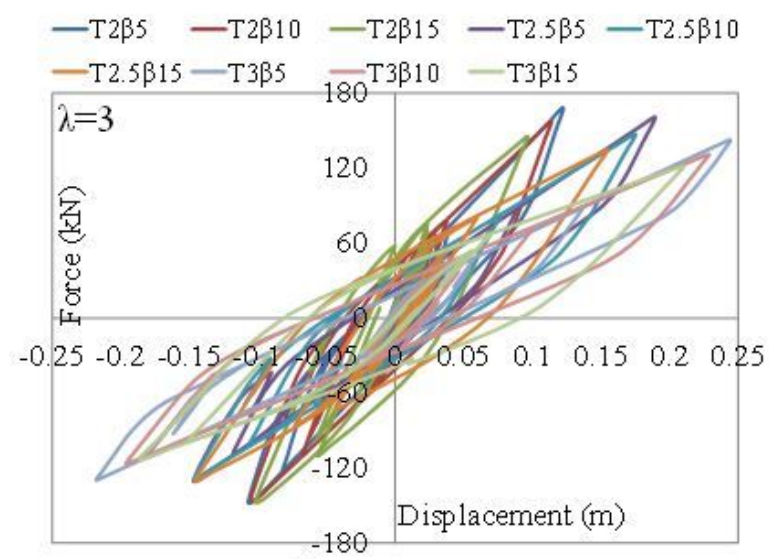

a)

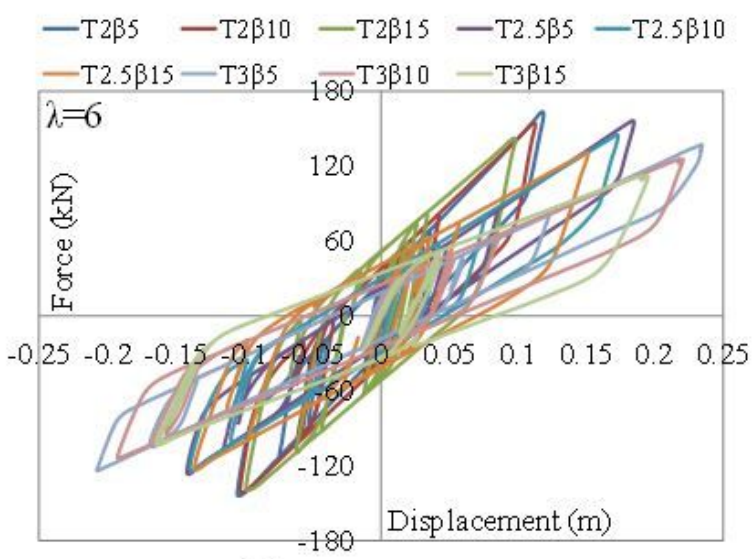

b)

\section{Figure 42}

Bi-linear force-deformation relation of 9-storey frame with HDRB under Gazlı earthquake. 